\title{
INVESTIGATIONS INTO GLIDER CHASSIS LOAD SPECTRUM
}

\author{
Wojciech Owczarek \\ Mirosław Rodzewicz \\ Warsaw University of Technology \\ Warsaw, Poland
}

\begin{abstract}
The paper describes investigations on load spectrum of a glider chassis during take-off and landing. The experiments were conducted on different kinds of airfield surfaces, and recorded time-courses of loads acting on the main and front gear were used for analysis. The paper shortly describes the tests carried out on a PW-6 glider (description of the measurement system installed on the glider main and front landing gear). There is included a comparison of different methods used for time-courses analysis and full cycle counting. The following methods were used: local extremes count method, level exceeds count method, full cycles count method, rainflow count method, and a method developed by the first author. The outputs generated by application of the above mentioned methods for different test-time-courses of load, and the real time-courses of load observed during take-off and landing, are described. Paper presents also load spectrum for the main gear for take-off and landing on a grassy runway. This load spectrum were used later on an experimental stand, build by the authors for fatigue tests of special shock-absorbing element, made from GFRP composite for a new glider.
\end{abstract}

\section{GOAL OF THE RESEARCH}

The research goal was to study the load spectrum applied onto a glider chassis during takeoffs and landings on different kinds of airfield surfaces, and comparison of different methods used to analyze the obtained load records.

The research contains a description of the tests carried out on a PW-6 glider (description of the measurement system installed on the glider main and front landing gear).

Data analysis included a comparison of different methods of post processing the load records. To analyze the data a set of software was developed that allowed to process the records using a particular method.

\section{Measuring elements}

Two strain gages were used in order to measure the loads applied on the main and front glider gear. The axis of the wheels were hollow allowing the gages to be placed at the inner wall (rys. 3.1.1). The strain gages were glued using $3 \mathrm{M}$ glue and epoxy resin, then pressed to the axis walls using an elastic sac filled with pressurized air. 


\section{Goal of investigations}

- study the load spectrum applied onto a glider chassis

- comparison of different methods used to analyze the obtained load records

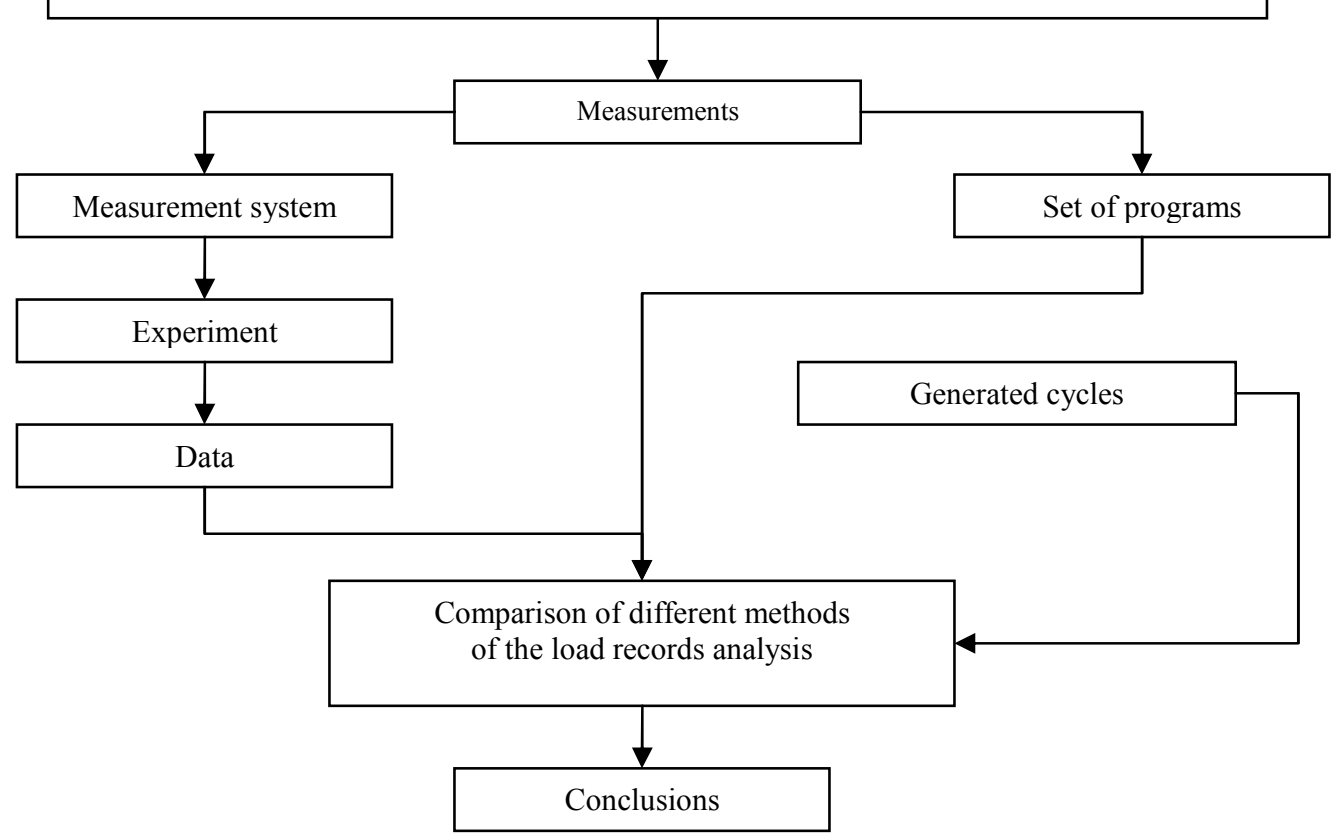

Fig. 1. Operational scheme

\section{MEASUREMENT SYSTEM}

\section{Goal:}

- $\quad$ Building a measurment system that will allow to record the load spectrum

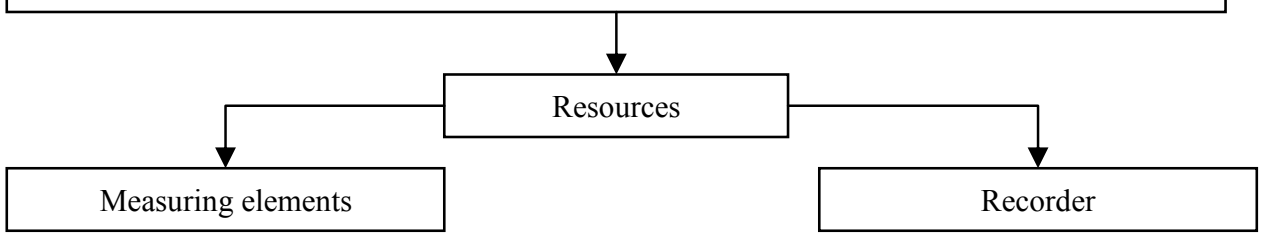

Fig. 2. Operational scheme

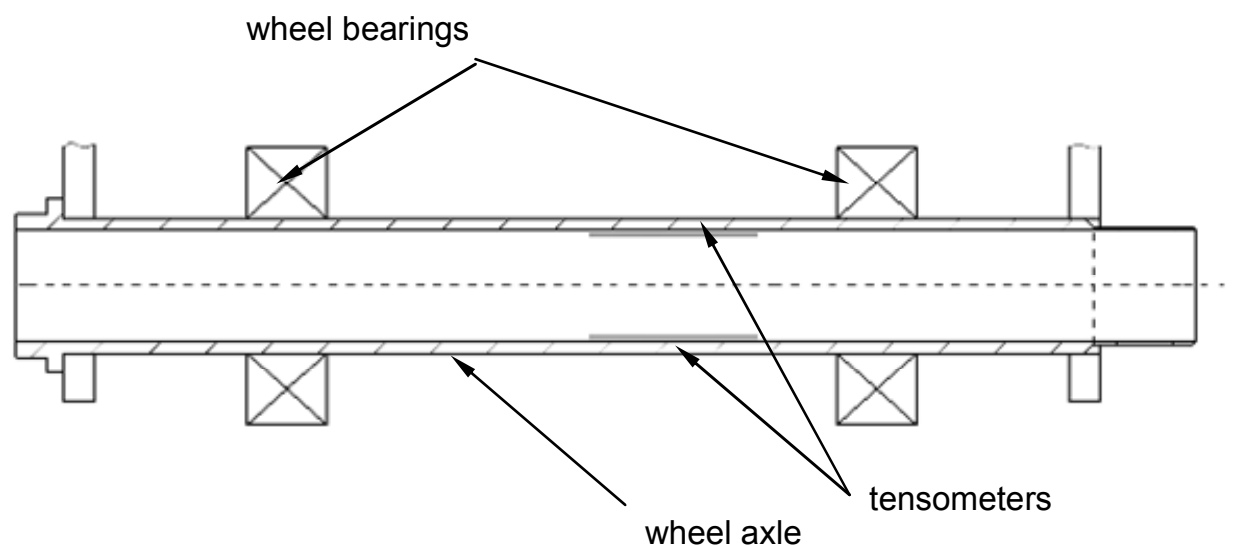

Fig. 3. Sketch of measured object 
The load applied on the wheel generates strains on the hollow axis. The strains were measured by resistance change in the strain gage. According to Hooke's law strains are proportional to stress and those depend on the forces acting on the wheel. Strain gages were placed between the hub bearing - where pure bending takes place. Additionaly the gages and two resistors formed a halfbridge, that compensate the resistance change caused by the temperature. The scheme of the connections is shown below (rys. 3.1.2)

\section{Recorder}

The signals from the main and front gear after amplification are recorded with Apek Al 154 recorder. The recorder has $4 \mathrm{Mb}$ memory, 16 channels and sampling period of $1 \mathrm{~ms}$. The photograph below (3.1.3) shows the separator box and the drawing below 3.1.4. the scheme of installation.

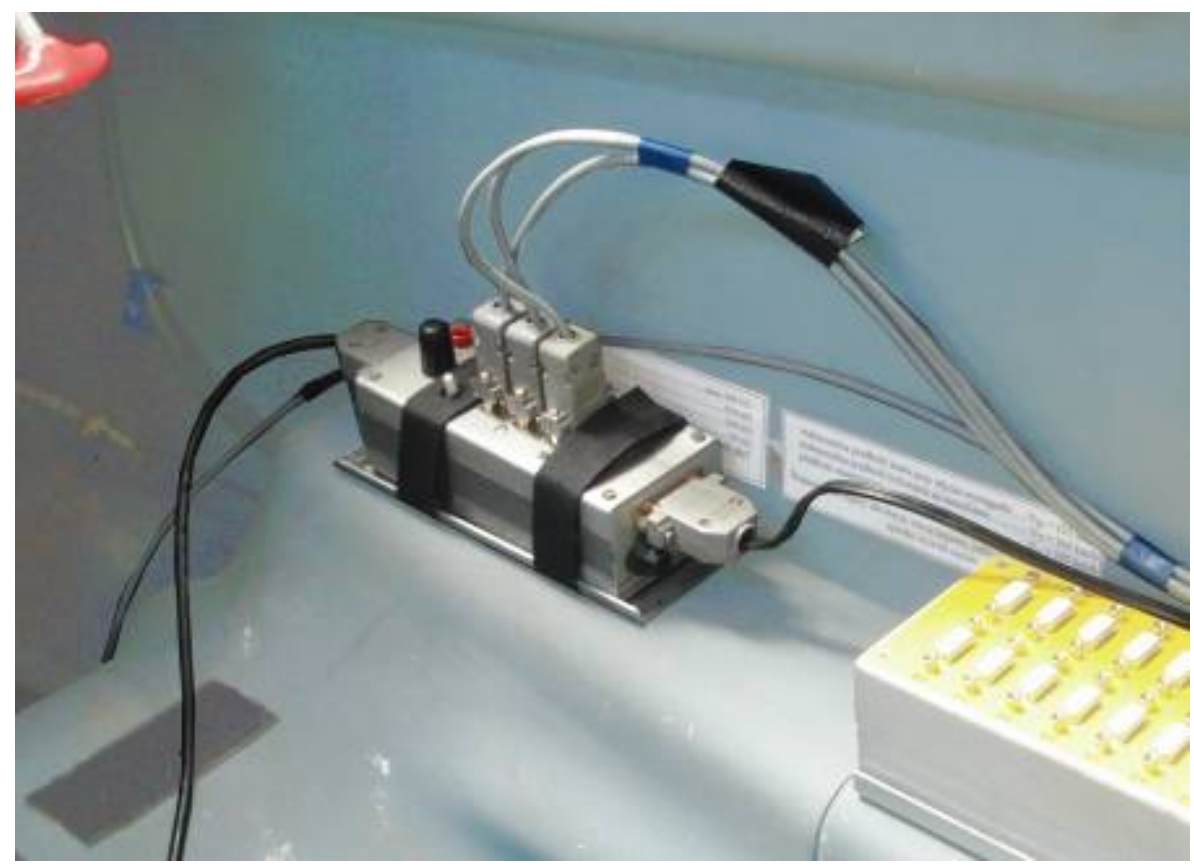

Fig. 4. Photo of measuring system mounted in the PW-6 glider

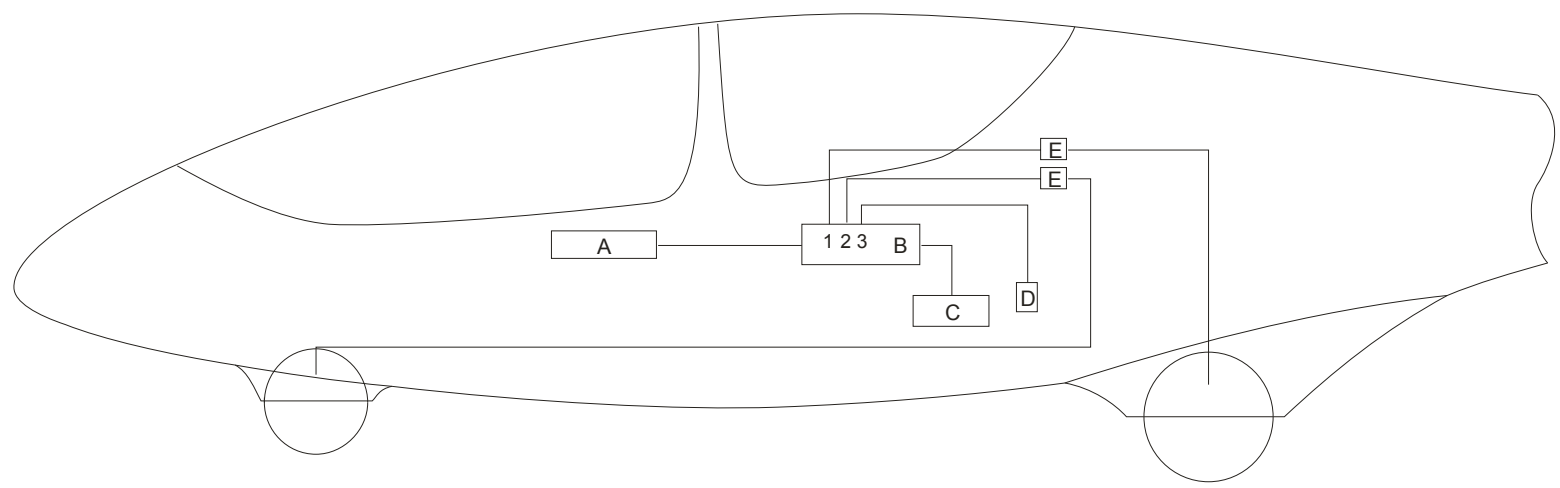

A - recorder

B - distributor

C - battery

D - accelerometer

E - signal amplifier

Fig.5. Whole measurement installation scheme 


\section{SET OF SOFTWARE}

Goal:

- $\quad$ Programming a software that should generate matrices for a chosen method

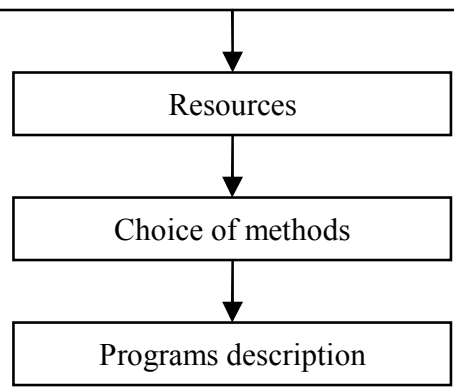

Fig. 6. Operational scheme

\section{Resources}

Every program was written in $\mathrm{C}++$. The Dev $\mathrm{C}++$ v. 4.9.7.0. compiler was used.

\section{Choice of methods}

To make the comparison of particular methods of Full Cycle Counting (FCC) possible a number of programs were written. The following outputs were compared:

- Transfer matrix

- envelope method (rain flow counting)

- local extremes Mount method (according to Fig.. 2.4.5f)

- level exceeds count method

- full cycles method

- method shown in [4], here named: ,, quasi rain flow counting”

The methods are representatives for different kinds of methods and they differ by the level of algorithm complexity.

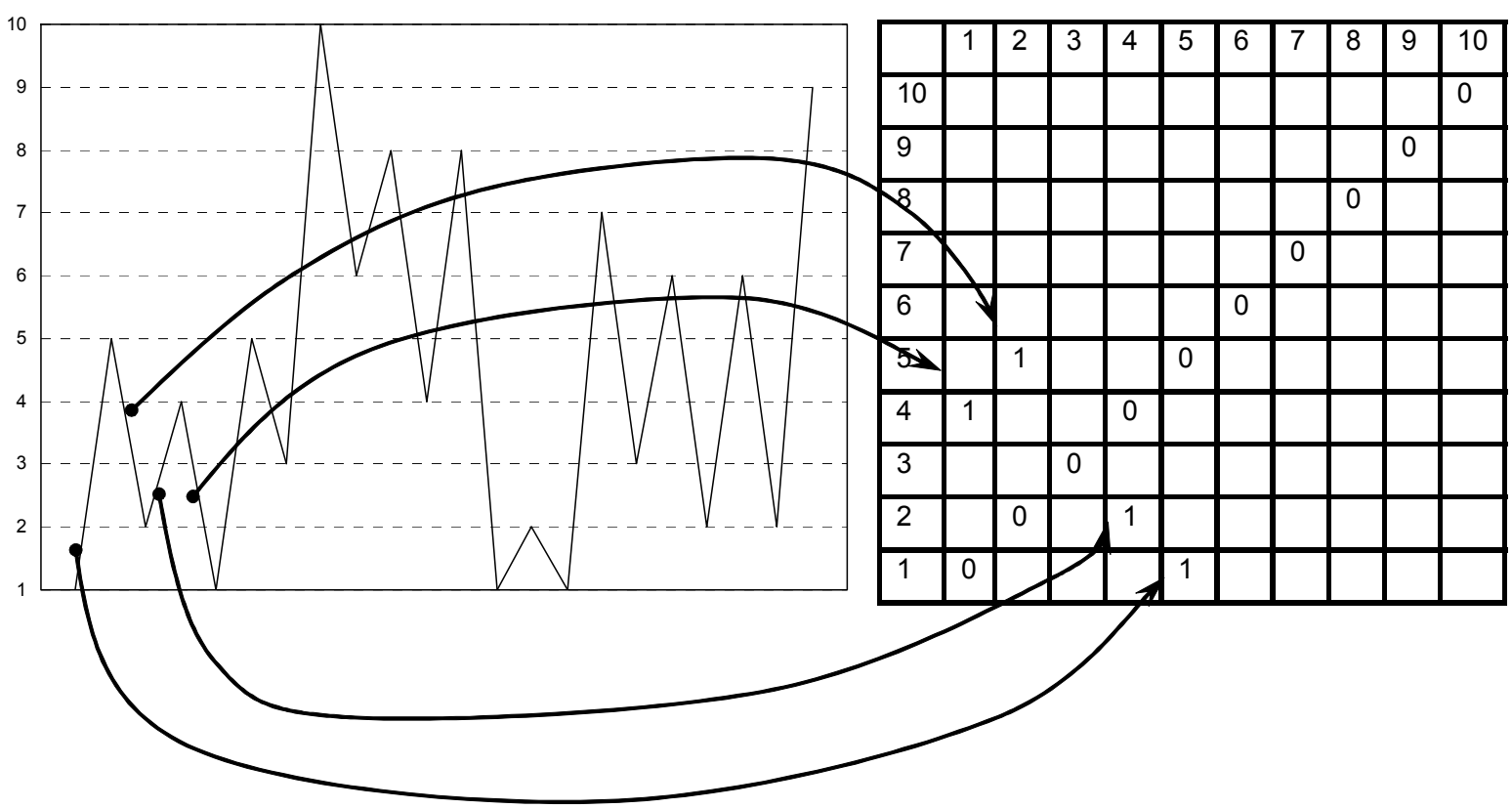

Fig. 7. Transfer array generation 
Methods description.

- Transfer matrix generation - the Basic form of data representation in form of a matrix. The matrix generation rule is shown above

- Full cycles method - determining sinusoidal cycles according to the procedure shown below:
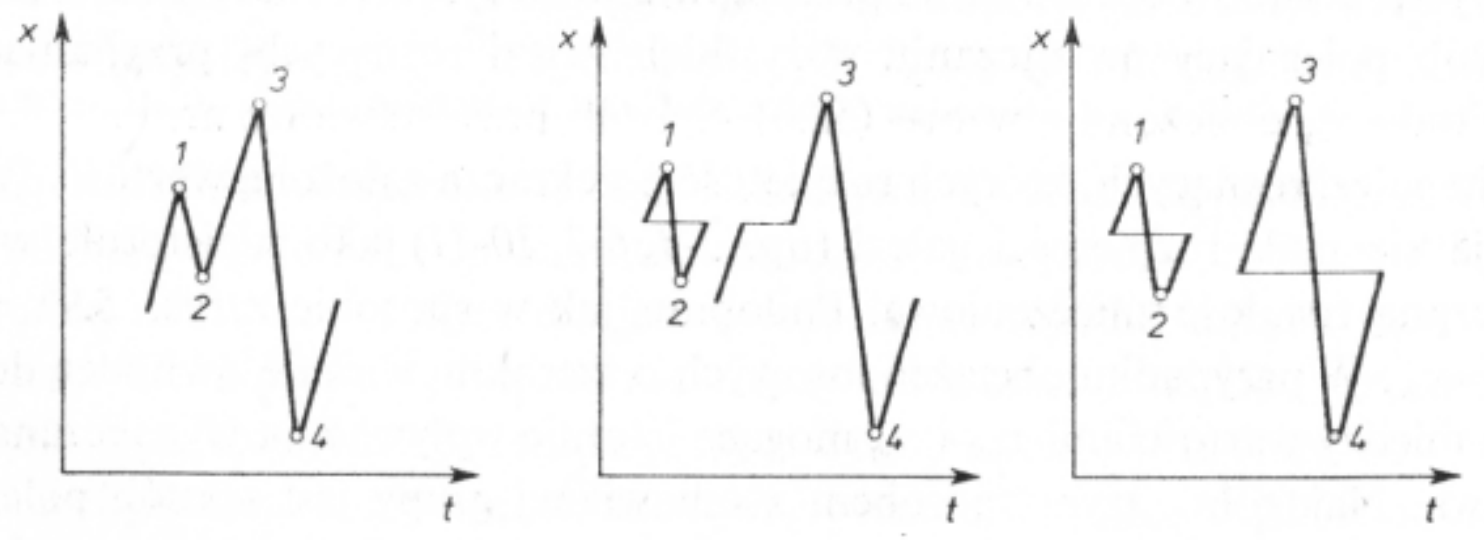

Fig. 8. Full cycle assembling

The division of the spectrum on sinusoidal cycles begins from the cycles with the smallest amplitude. In the following steps cycles of bigger amplitude are generated. The algorithm is shown below:

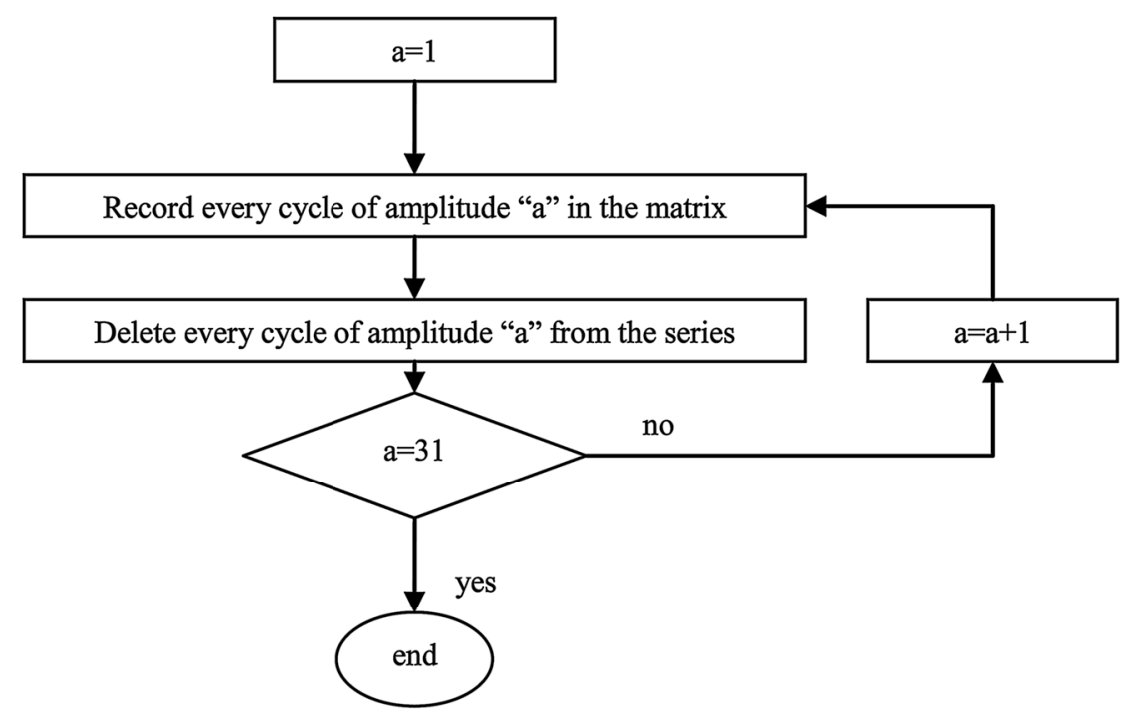

Fig. 9. Scheme of operation

- Local extremes count method - local extremes are counted relative to the mean value of loads. 


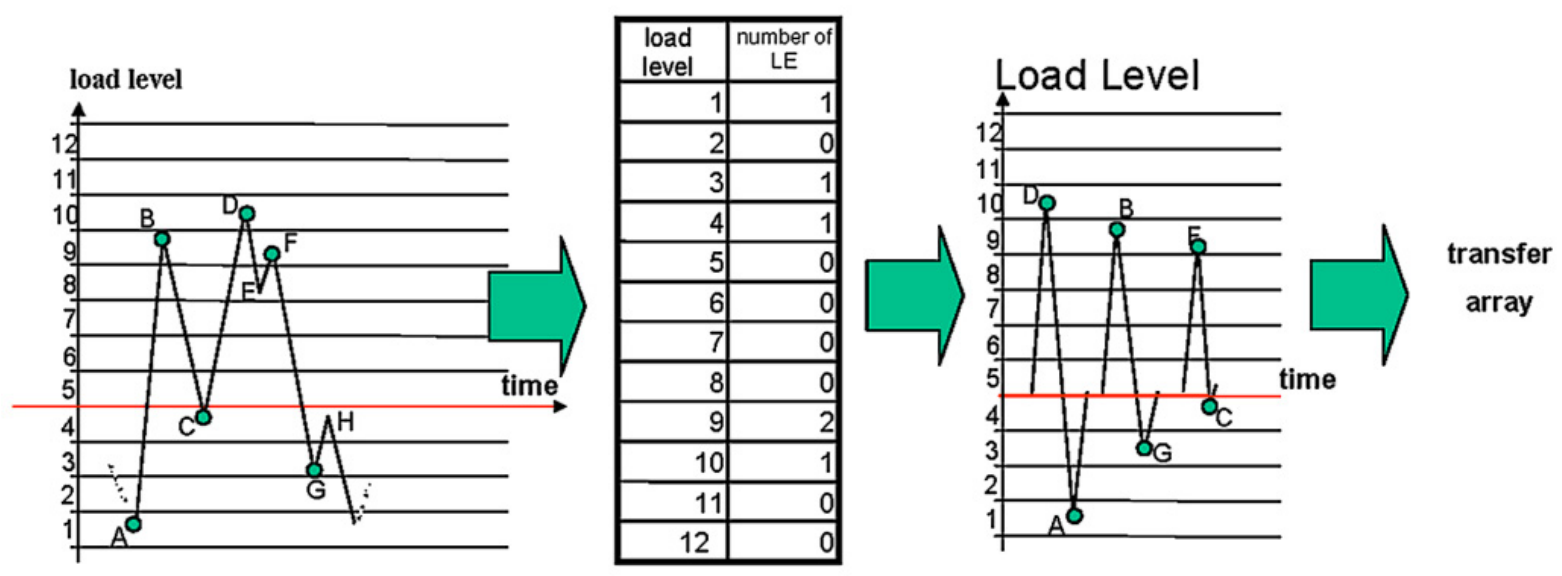

Fig. 10. Local extremes counting method

- Level exceeds count method - a similar to local extremes count method. In this case however the level exceeds are being counted.

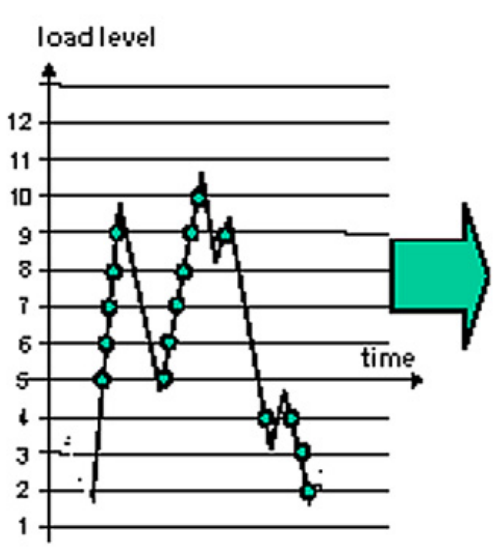

\begin{tabular}{|r|r|}
\hline $\begin{array}{c}\text { bad } \\
\text { buel }\end{array}$ & $\begin{array}{r}\text { umber or } \\
\text { kuu. ex. }\end{array}$ \\
\hline 1 & 0 \\
\hline 2 & 1 \\
\hline 3 & 1 \\
\hline 4 & 2 \\
\hline 5 & 2 \\
\hline 6 & 2 \\
\hline 7 & 2 \\
\hline 8 & 2 \\
\hline 9 & 3 \\
\hline 10 & 1 \\
\hline 11 & 0 \\
\hline & 0 \\
\hline
\end{tabular}

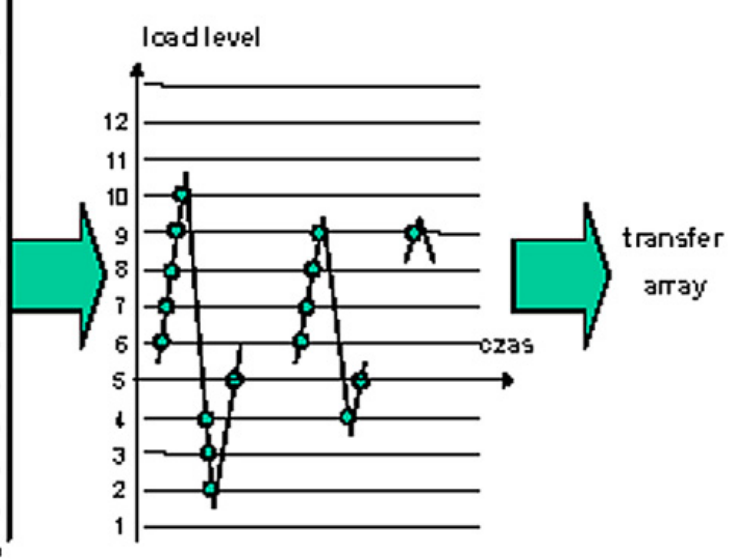

Fig. 11. Level exceeds counting method

- Rainflow counting method - in this method additionally a half-cycles are defined except of full cycles. The half-cycles are defined by a particular graph envelope (similar to rain flowing down a roof) 


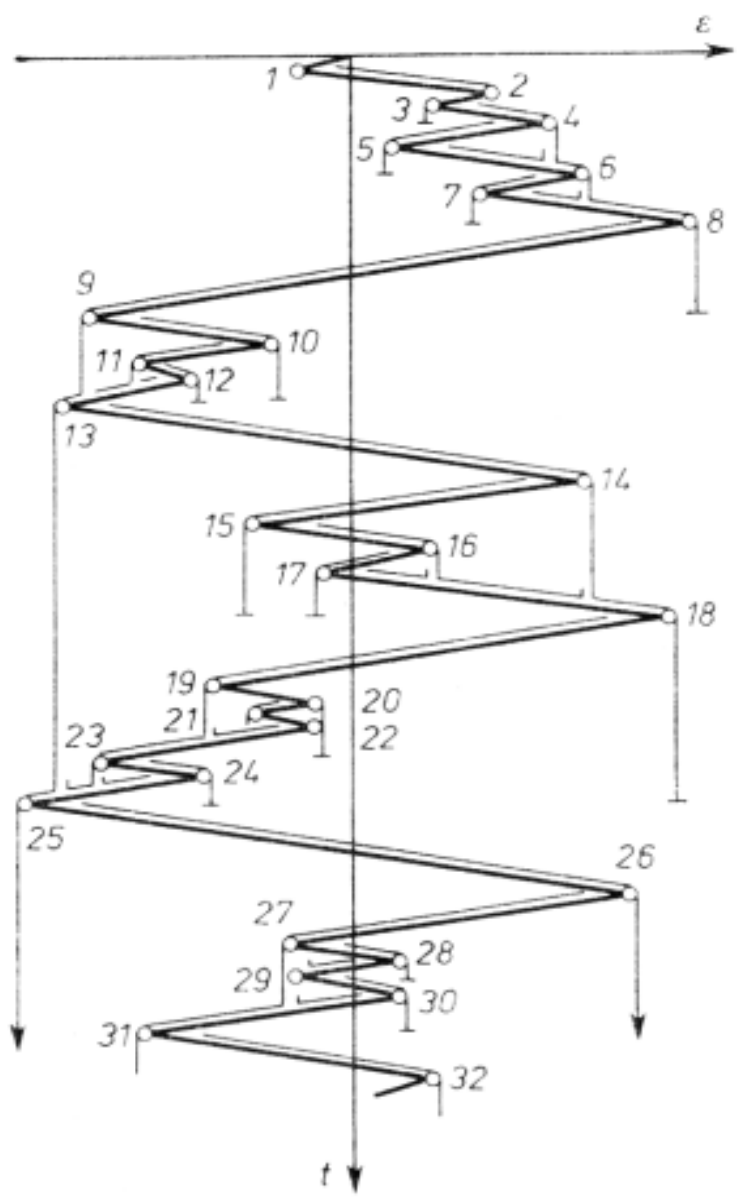

Fig. 12. Rainflow counting method

- Quasi rainflow counting method - works similar to the rainflow counting method but all the operations are made on the transfer matrix, where the method goes through the matrix cells and looks for pairs for the half-cycles.

\section{RESEARCH}

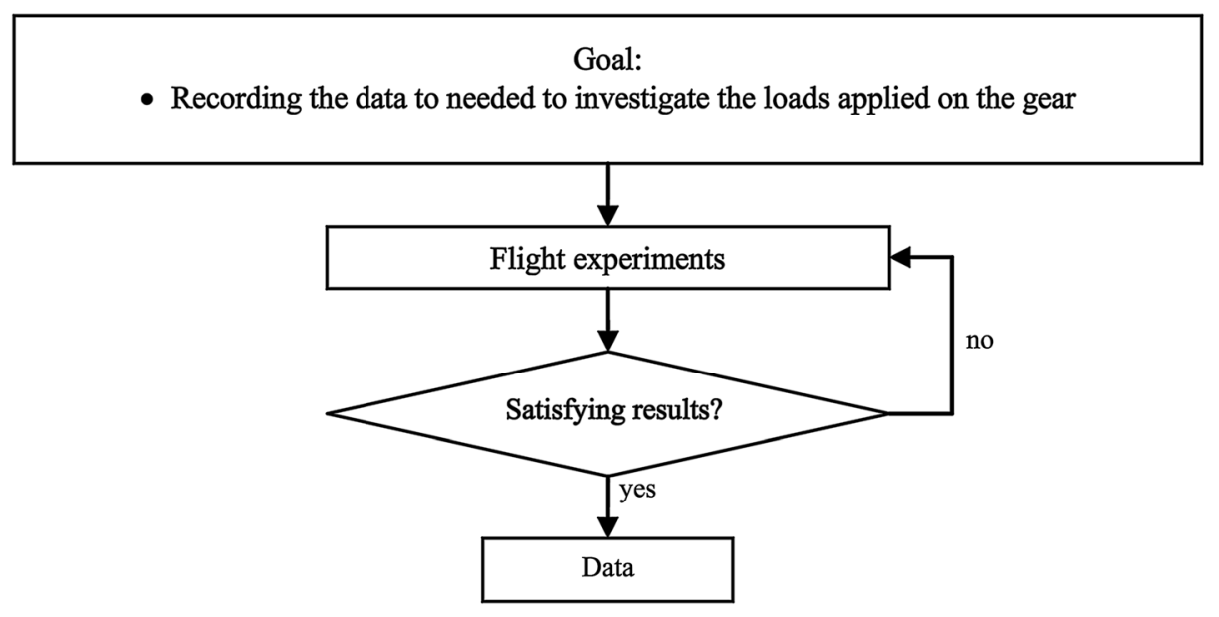

Fig. 13. Operational scheme

\section{Flight experiments}

Flight experiments were taken on a grassy air field. The data was collected Turing six landings and takeoffs of the glider. During the recordings the sampling frequency was set to $100 \mathrm{~Hz}$. 


\section{Data}

An example of load distribution is shown below. The graphs show the voltage values (in $\mathrm{mV}$ ) of signals generated by the main gear, front gear, accelerometer, and speedometer (based on pressure measurements).
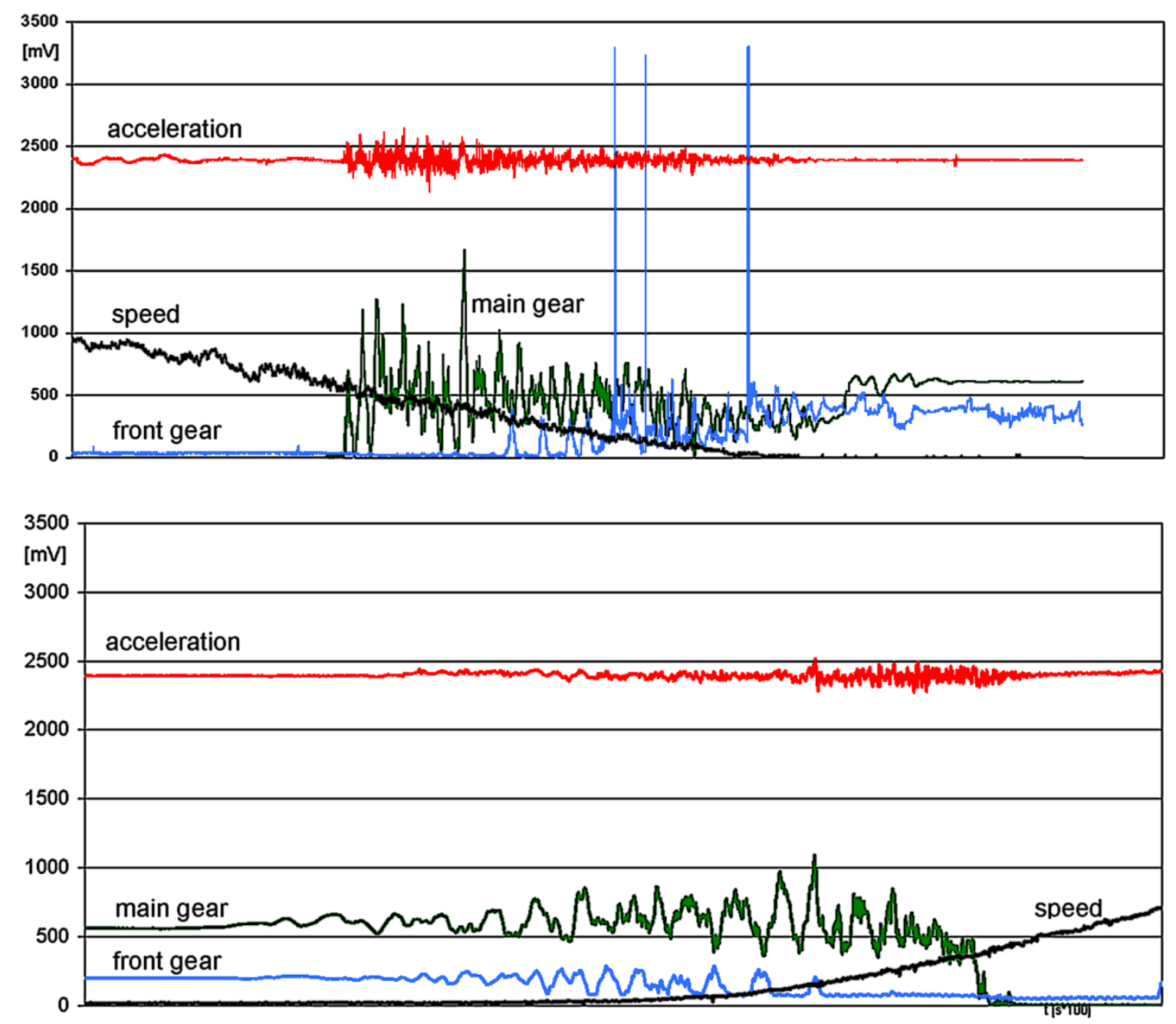

Fig. 14. Sample of registered signals

\section{COMPARISON OF METHODS USED TO PROCESS THE LOAD RECORDS}

\section{Series}

The analysis was made on artificial generated series having different character (series 1-5) and a series generated based on the experiment records (series 6). Series 2 and 3 show the same load cycle, one of them is just scaled. Series 6 was generated by joining all the experiments records in a chronological manner.

\section{Analysis}

Based on the series a transfer matrices were generated (appropriate for each method described in chapter 3.). By the use of the matrix of singular damages (according to Wohler's graph) a cumulated damage D was calculated according to Palmgren-Miner hypothesis. Compared values of D for corresponding methods are shown on graphs 16-27. Graph 28 shows the ratio of D (each single for a single investigated method) to the value of $\mathrm{D}$ taken from the transfer matrix (treated as the most basic one) as a function of I coefficient (I is the ratio of the number of local extremes over the number of mean value exceeds in time) 
Goal:

- Comparison of different methods processing random series of load records

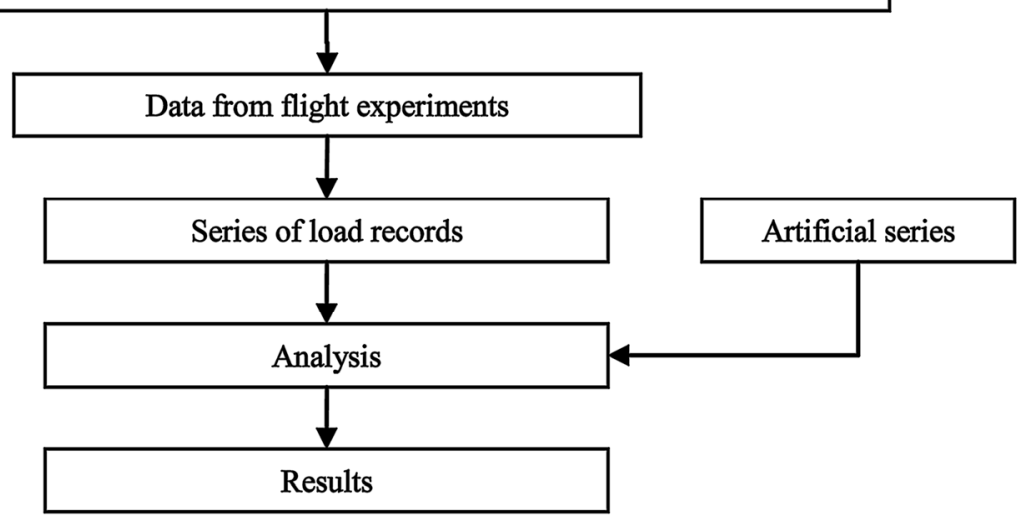

Fig. 15. Operational diagram

$\mathrm{I}=0,273$

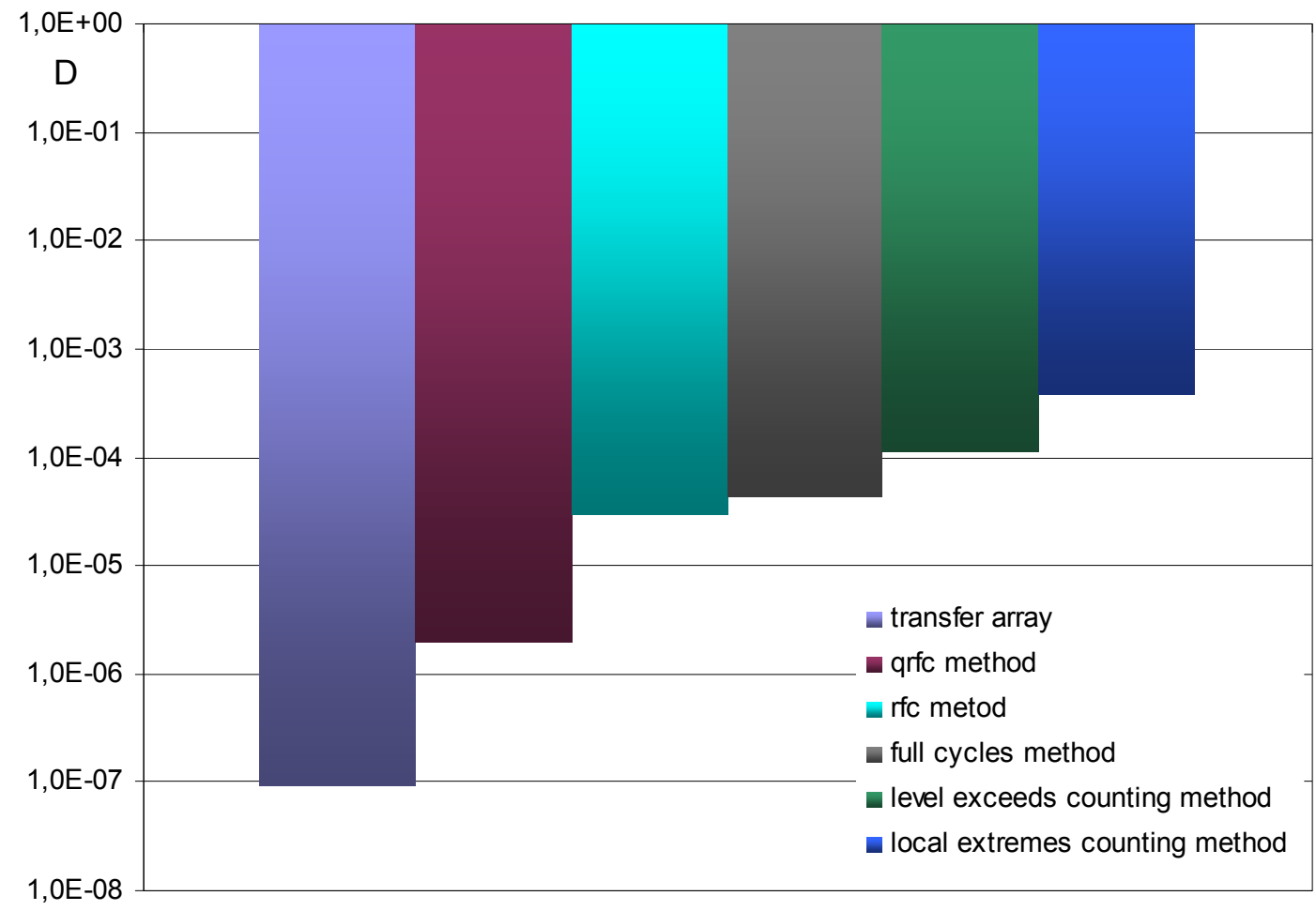

Fig.16. Damage values for different FCC methods - series 1 


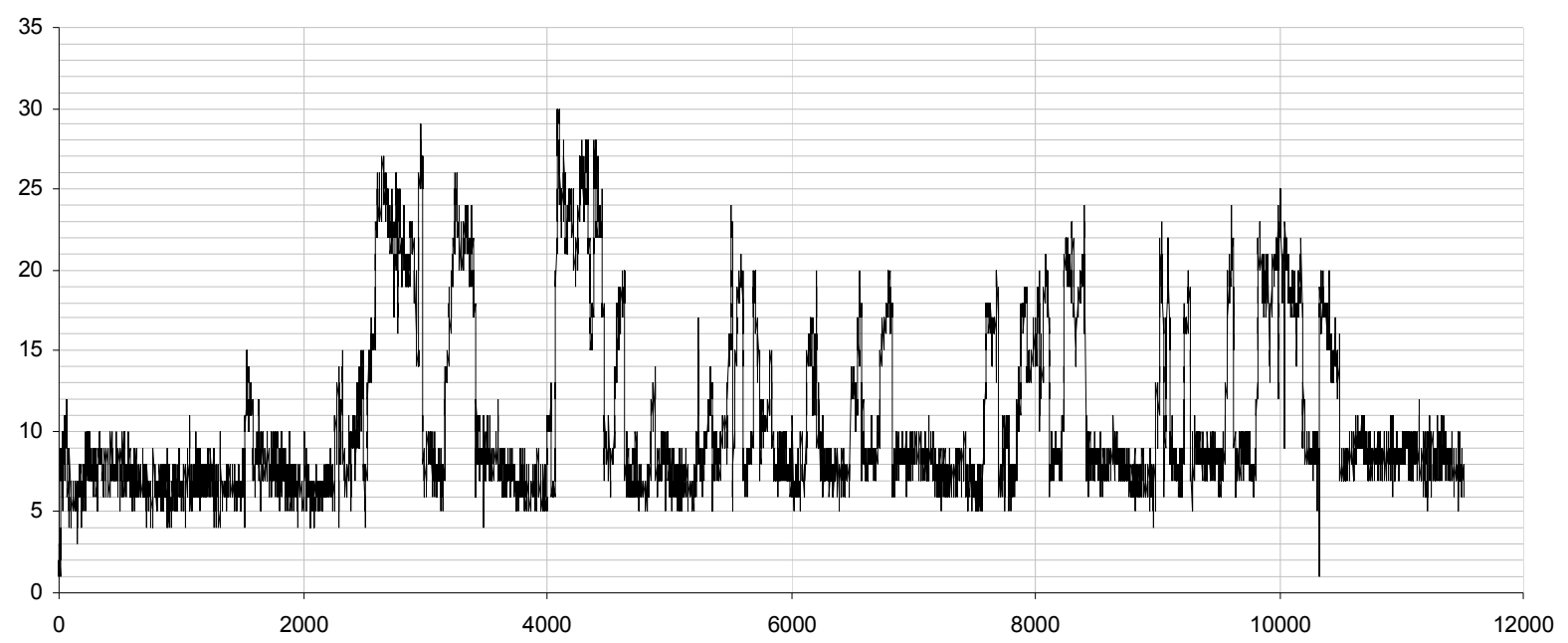

Fig.17. Series 1

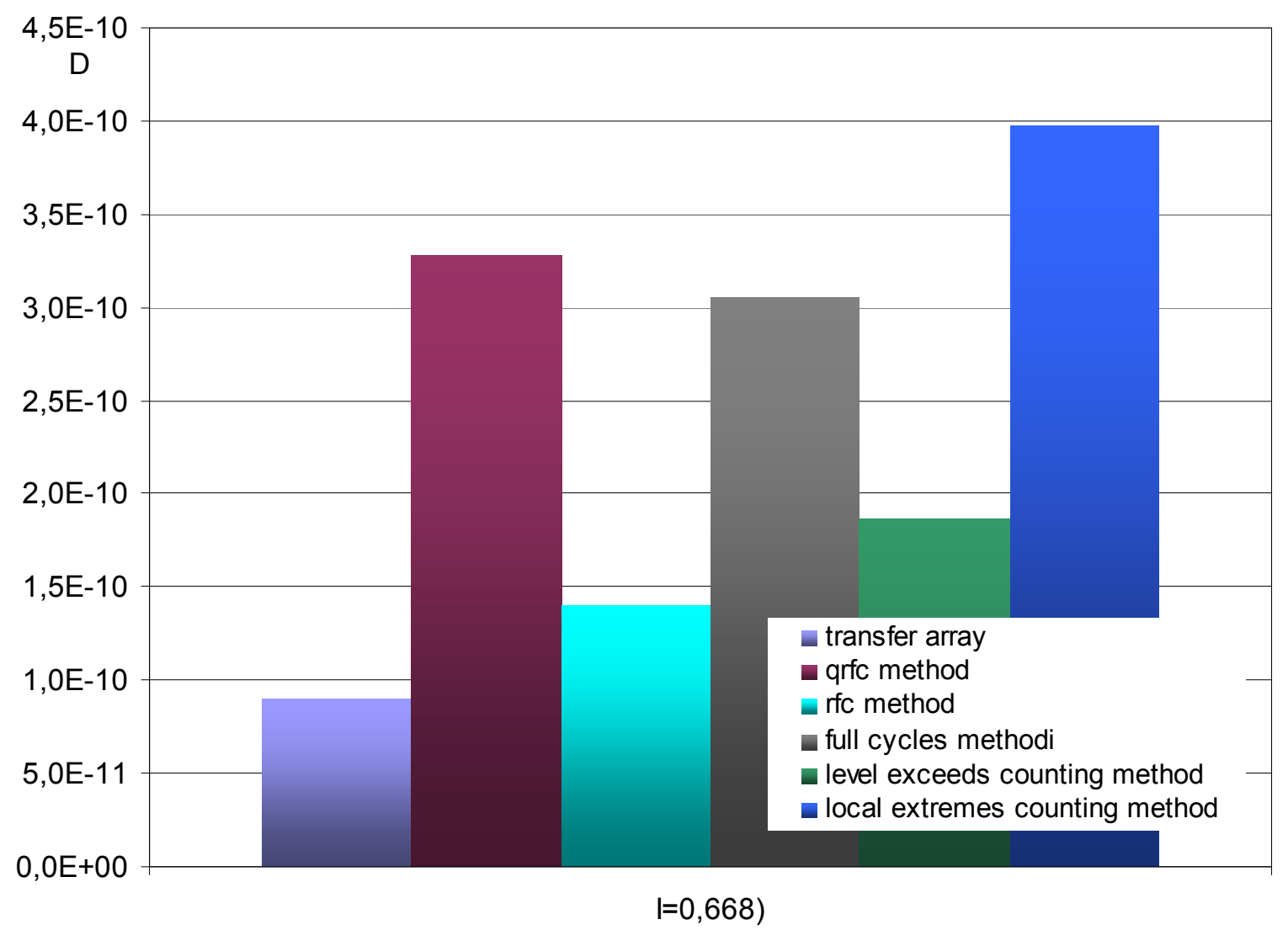

Fig.18. Damage values for different FCC methods - series 2 


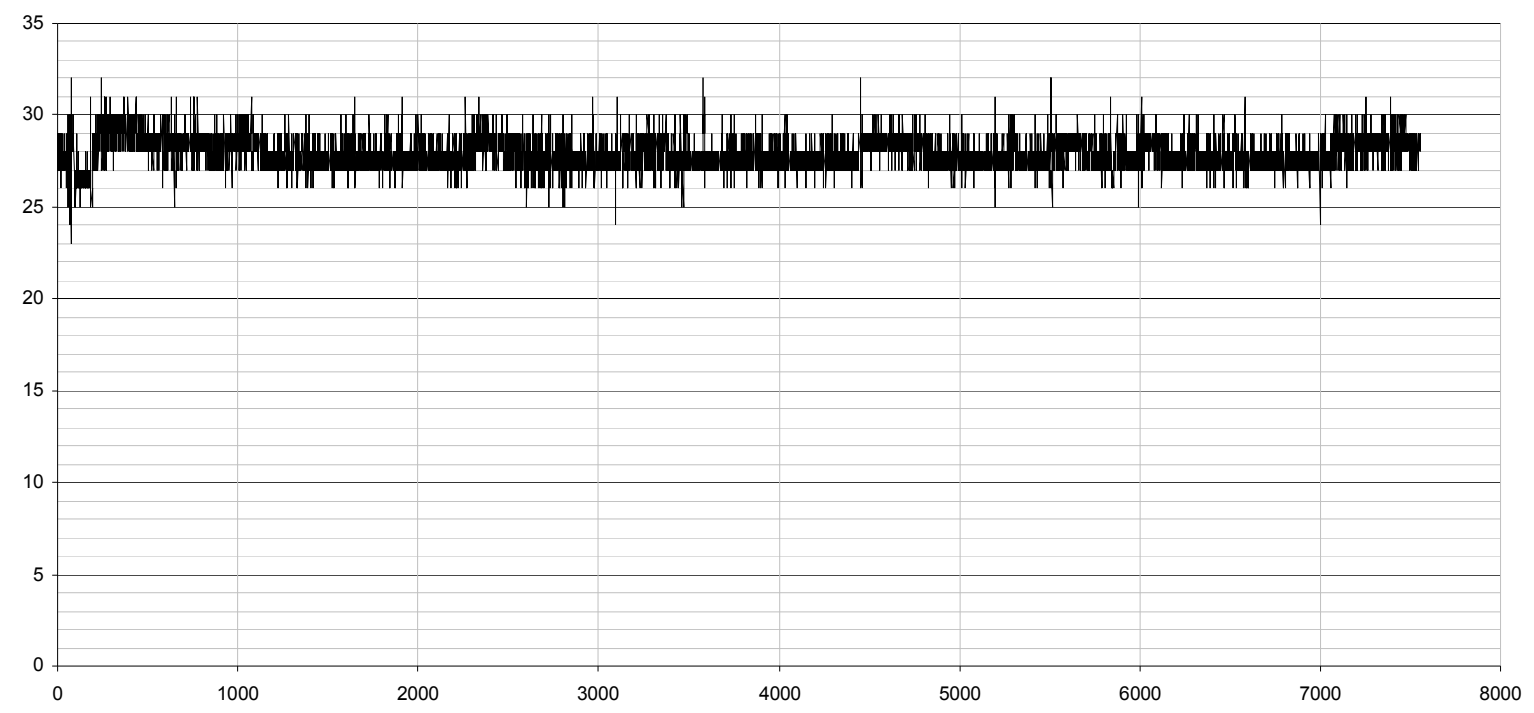

Fig.19. Series 2

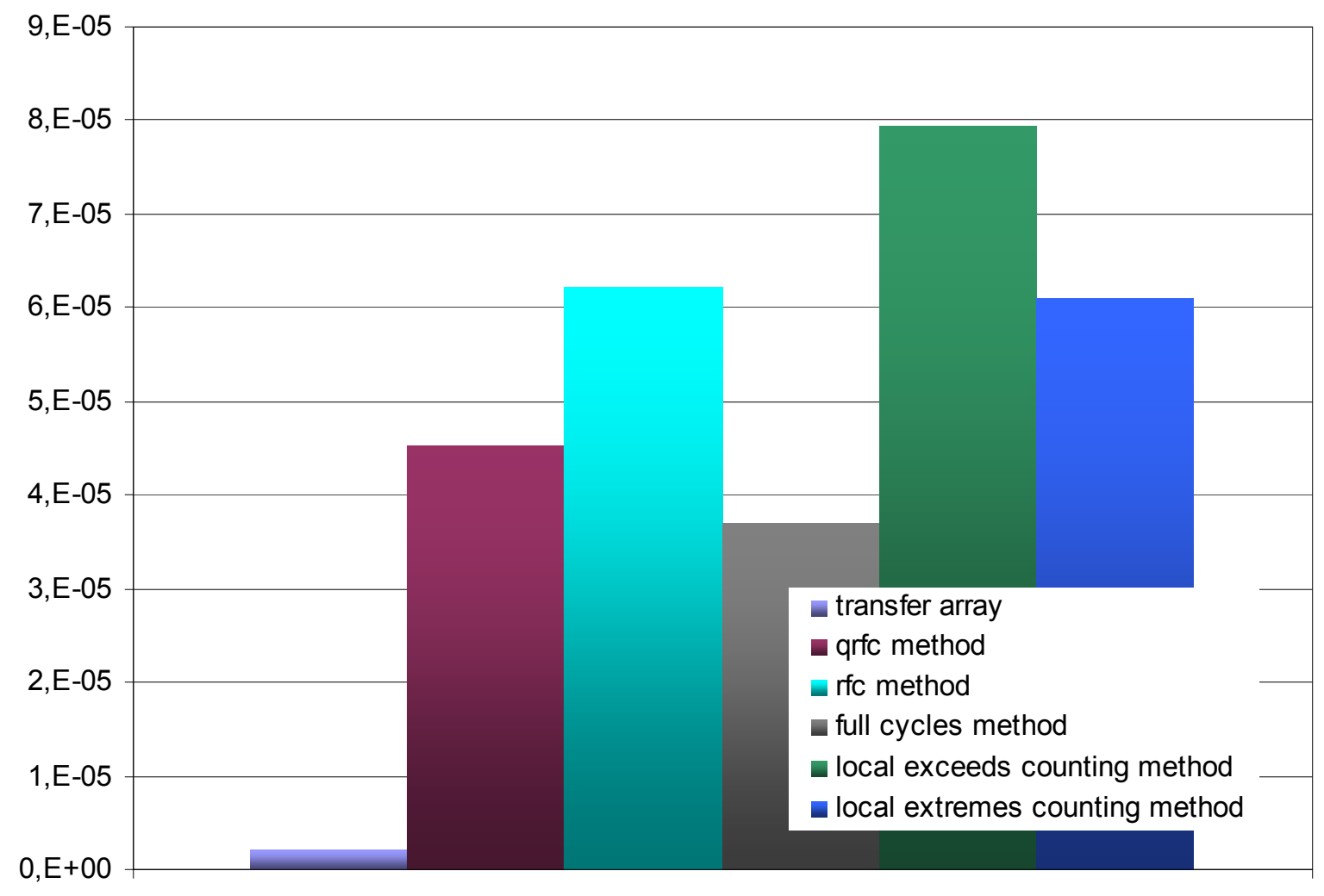

$\mathrm{l}=0,477$

Fig. 20. Damage values for different FCC methods - series 3 


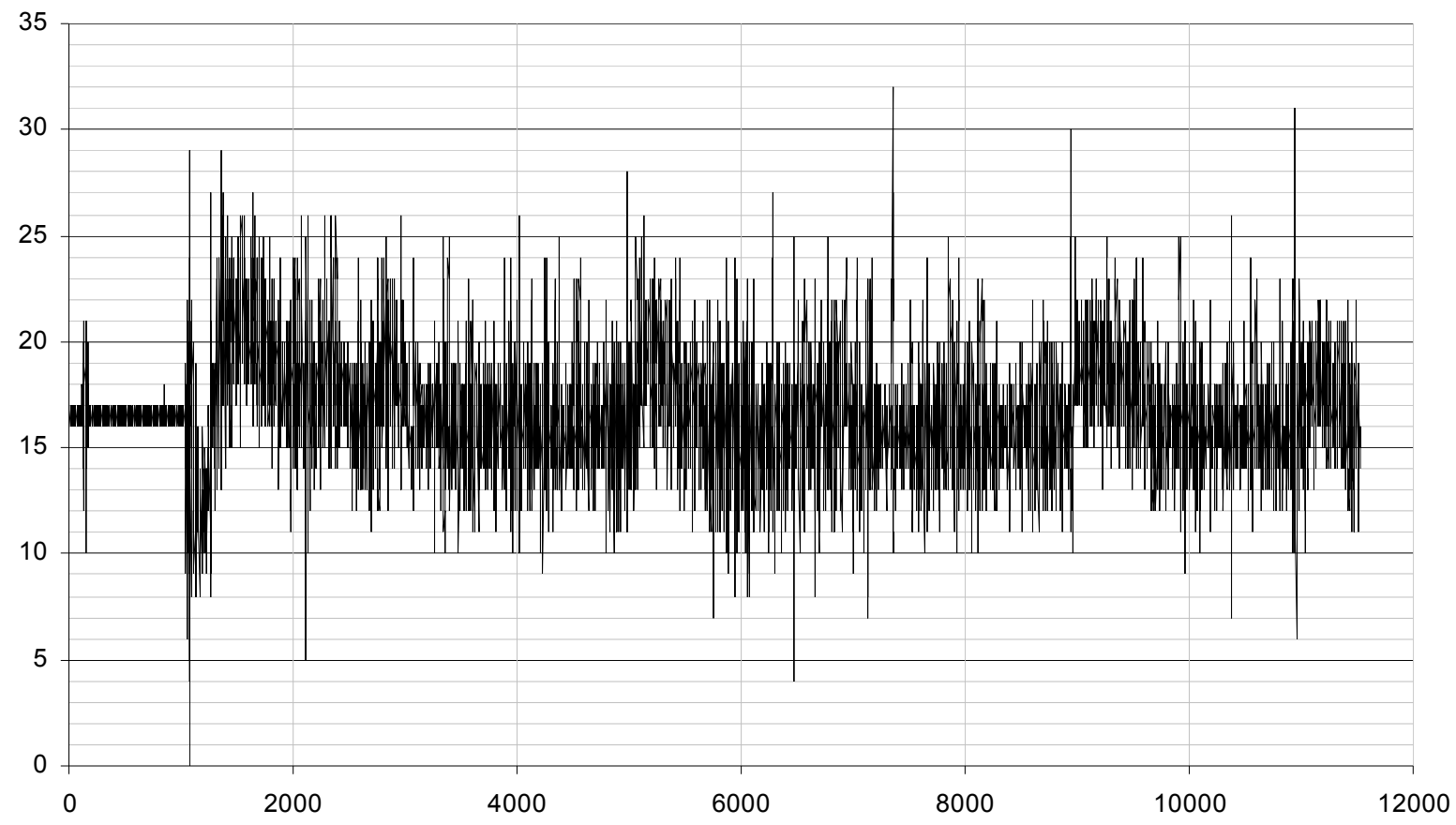

Fig. 21. Series 3

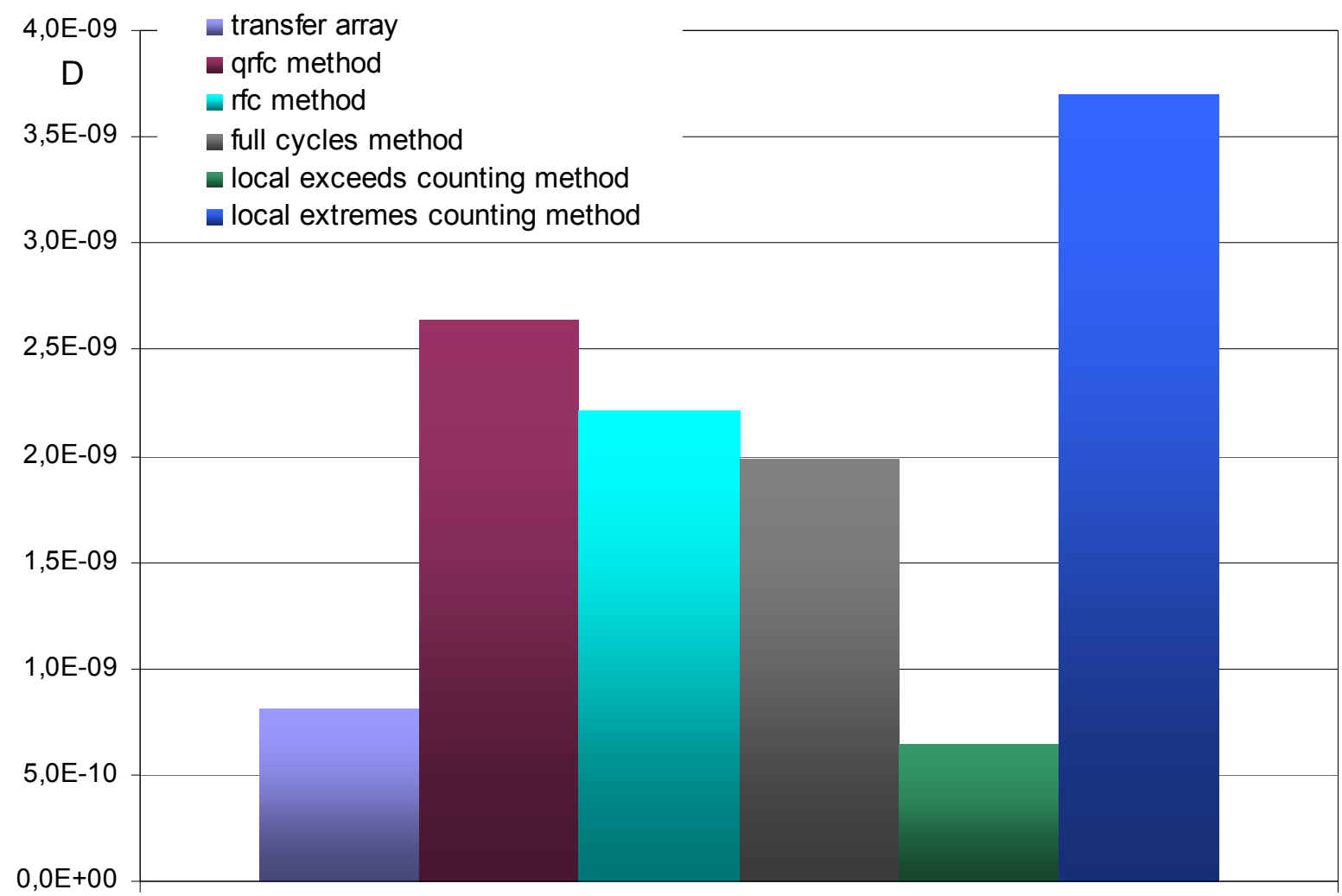

$\mathrm{l}=0,58$

Fig. 22. Damage values for different FCC methods - series 4 


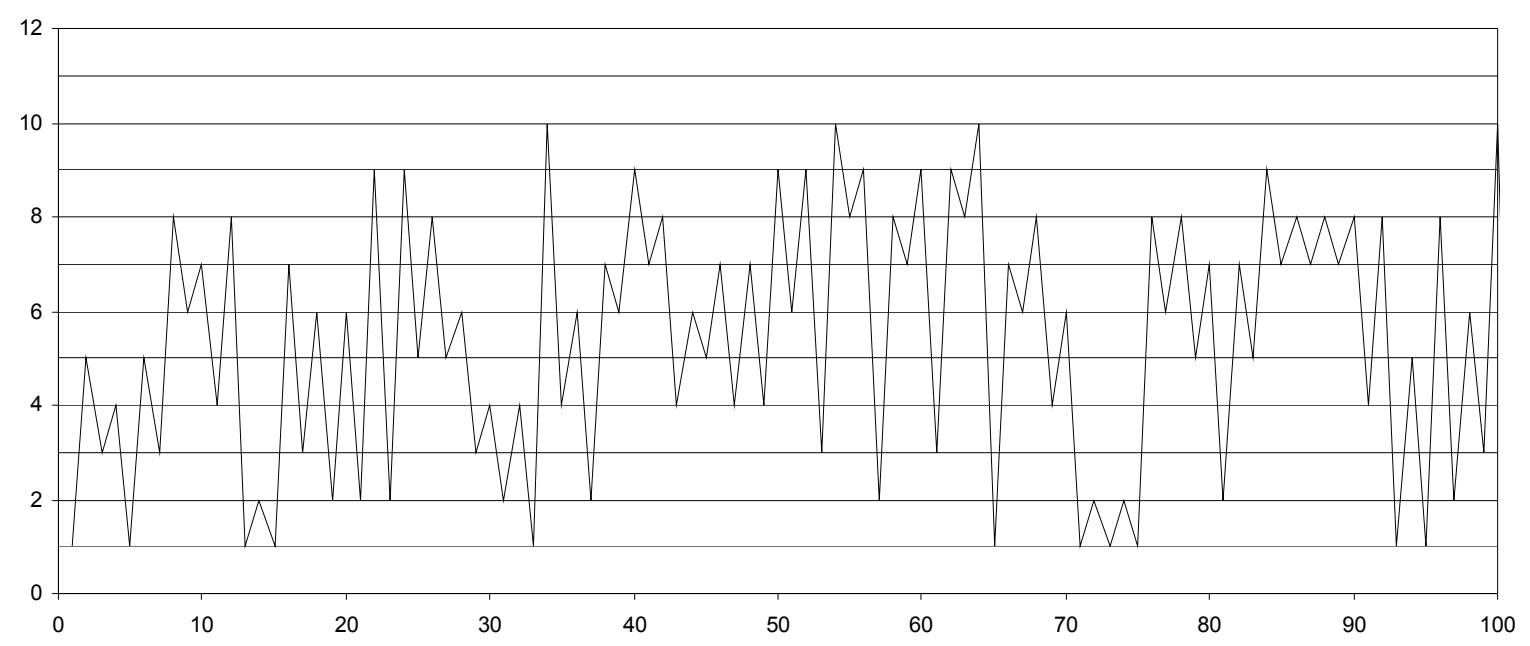

Fig. 23. Series 4

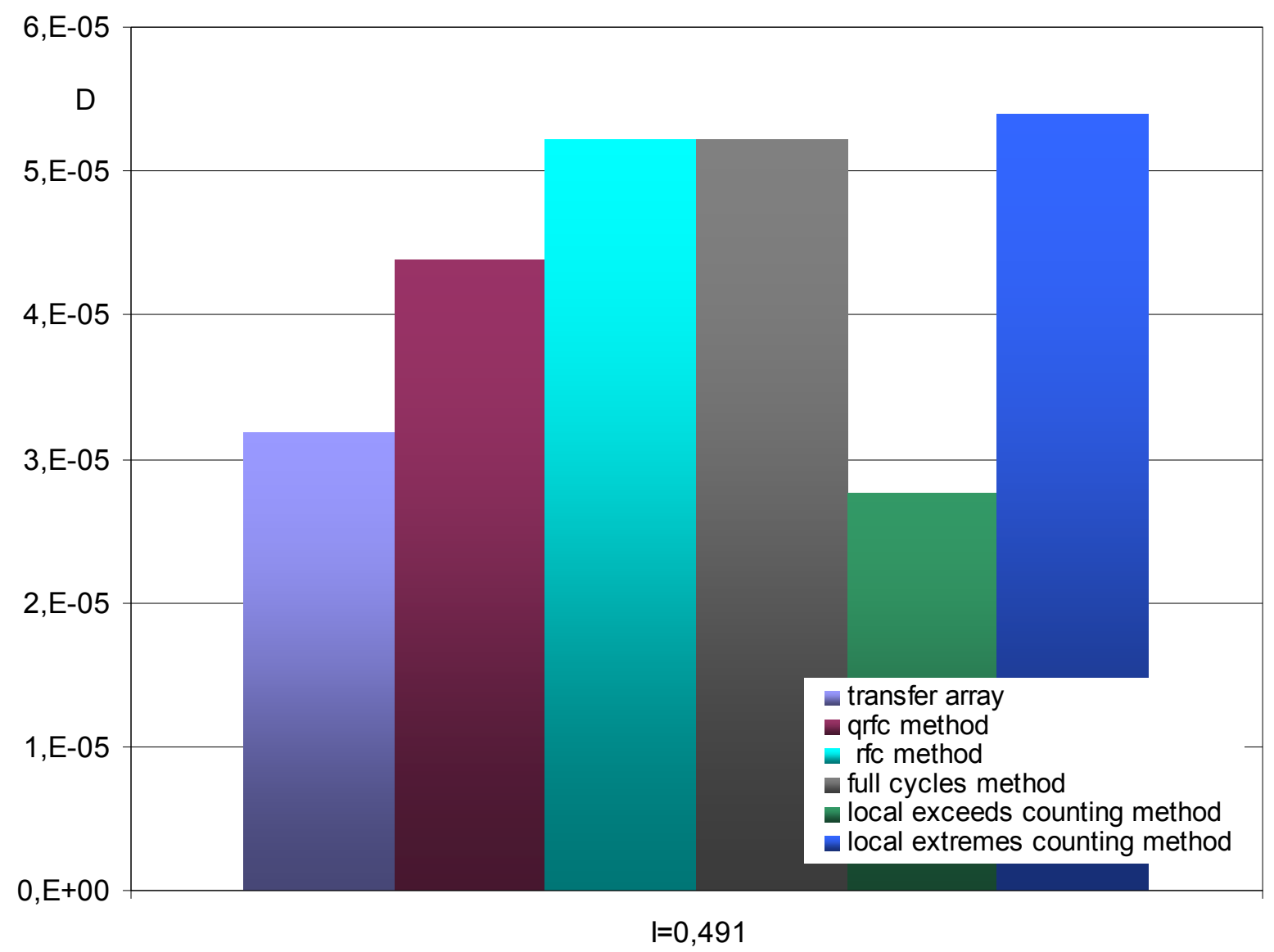

Fig.24. Damage values for different FCC methods - series 5 


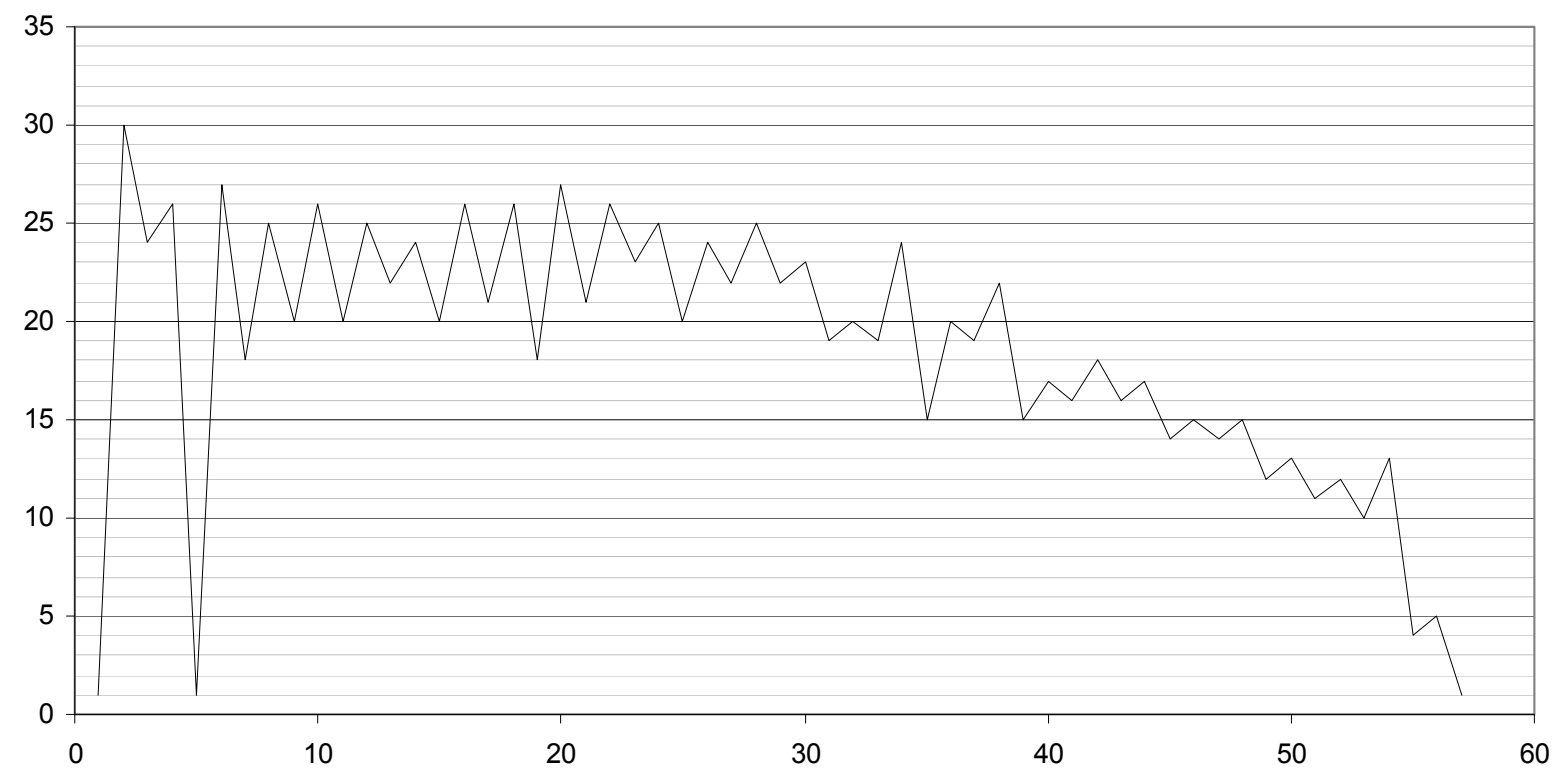

Fig. 25. Series 5

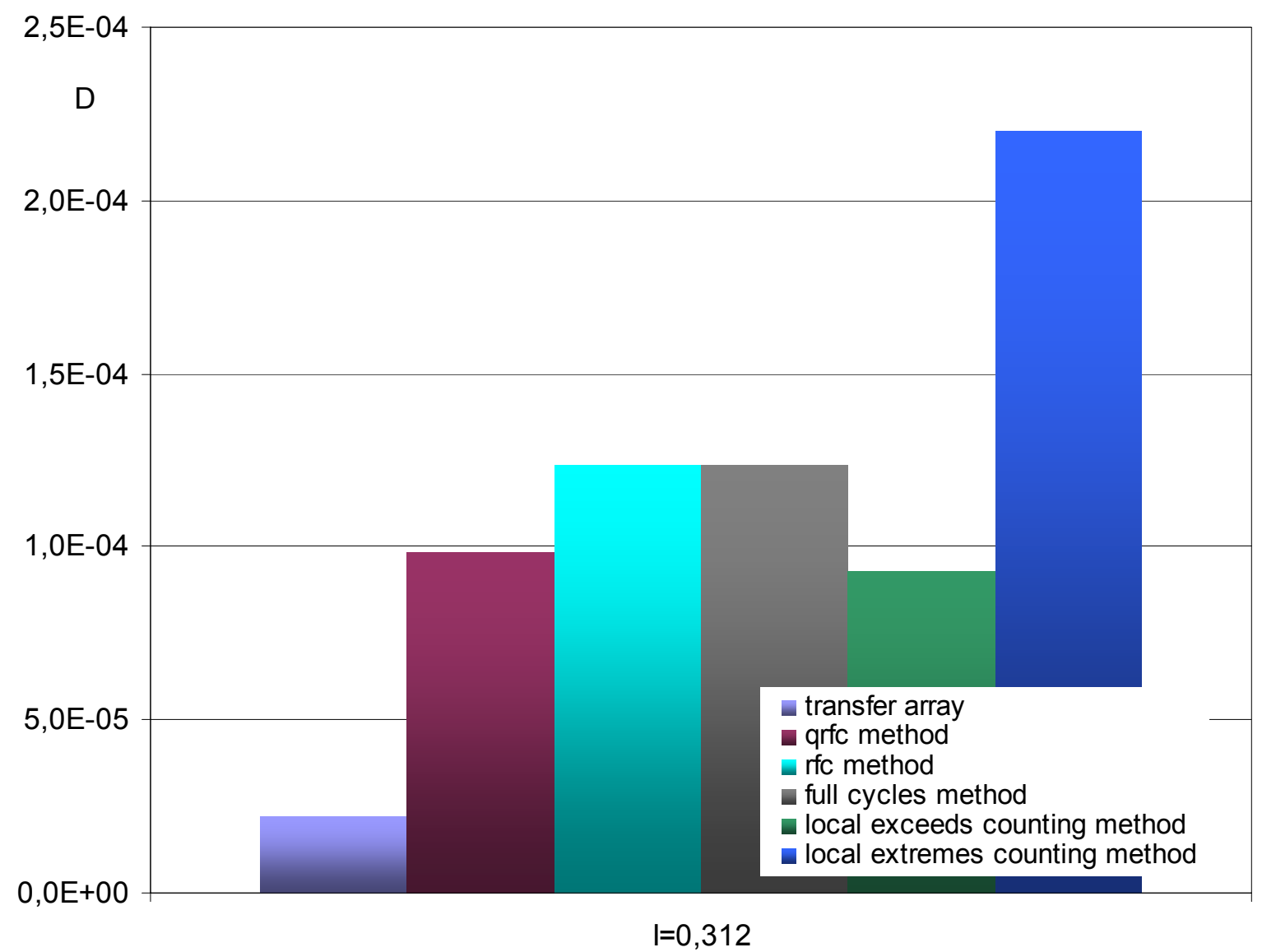

Fig.26. Damage values for different FCC methods - series 6 


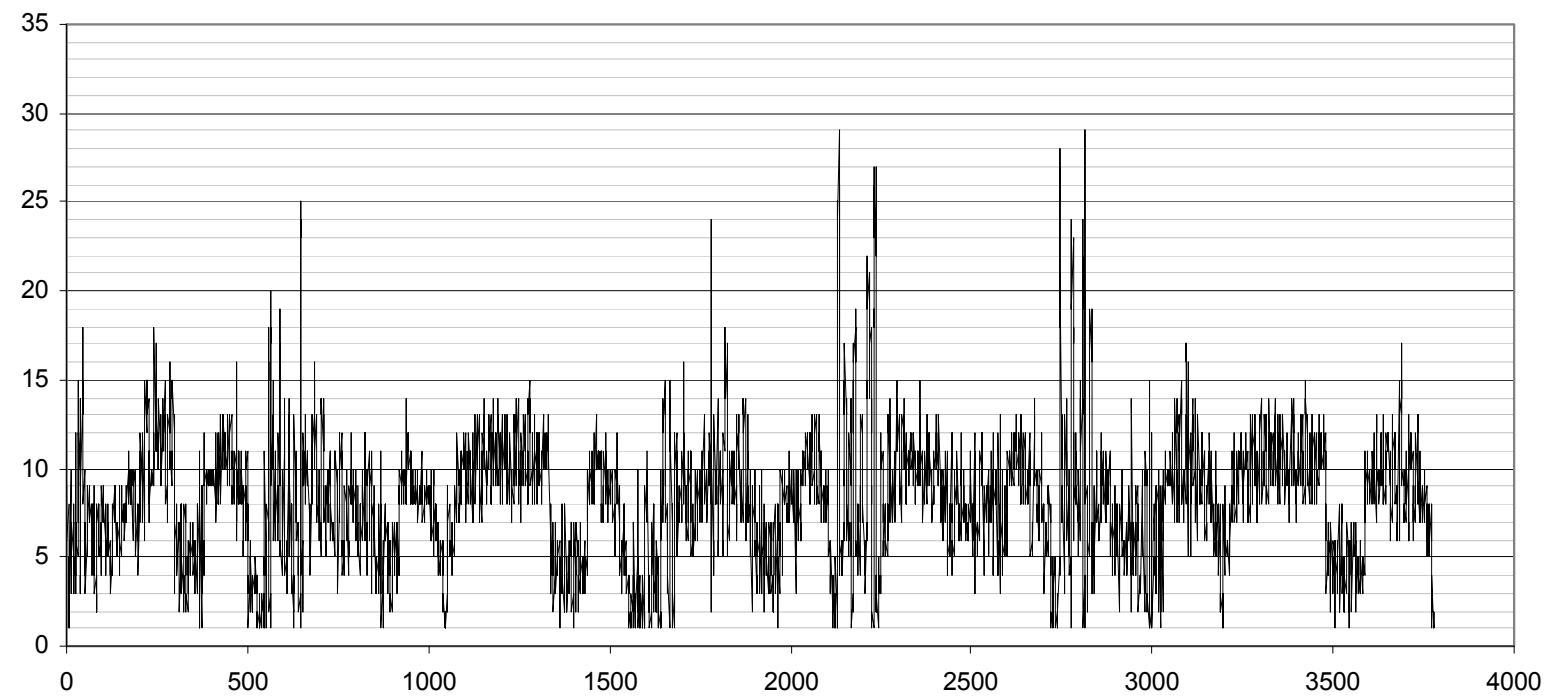

Fig. 27. Series 6

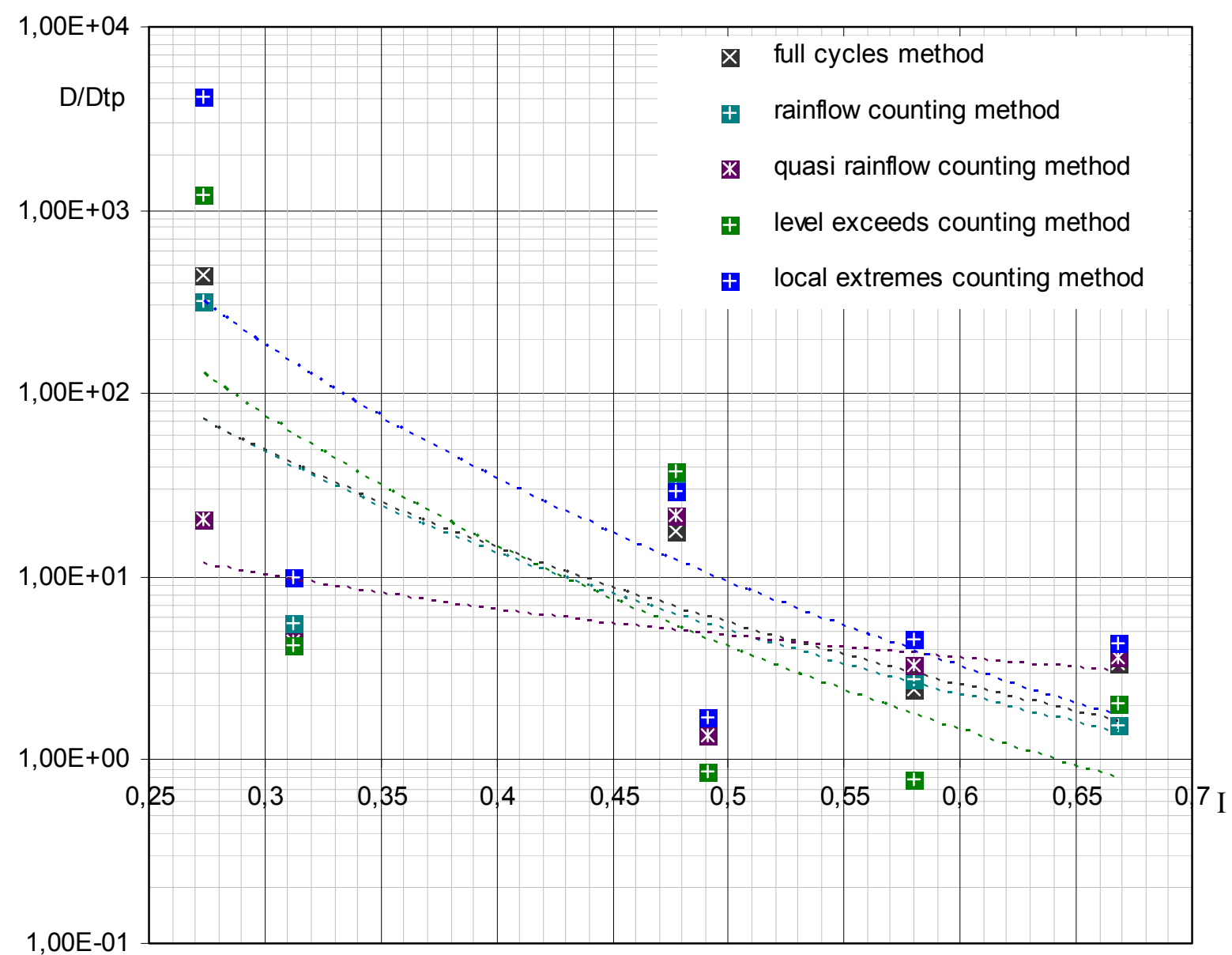

Fig. 28. Final comparison of FCC methods 
To picture the difference between the methods, graphs of matrices generated with series 3 are shown below.

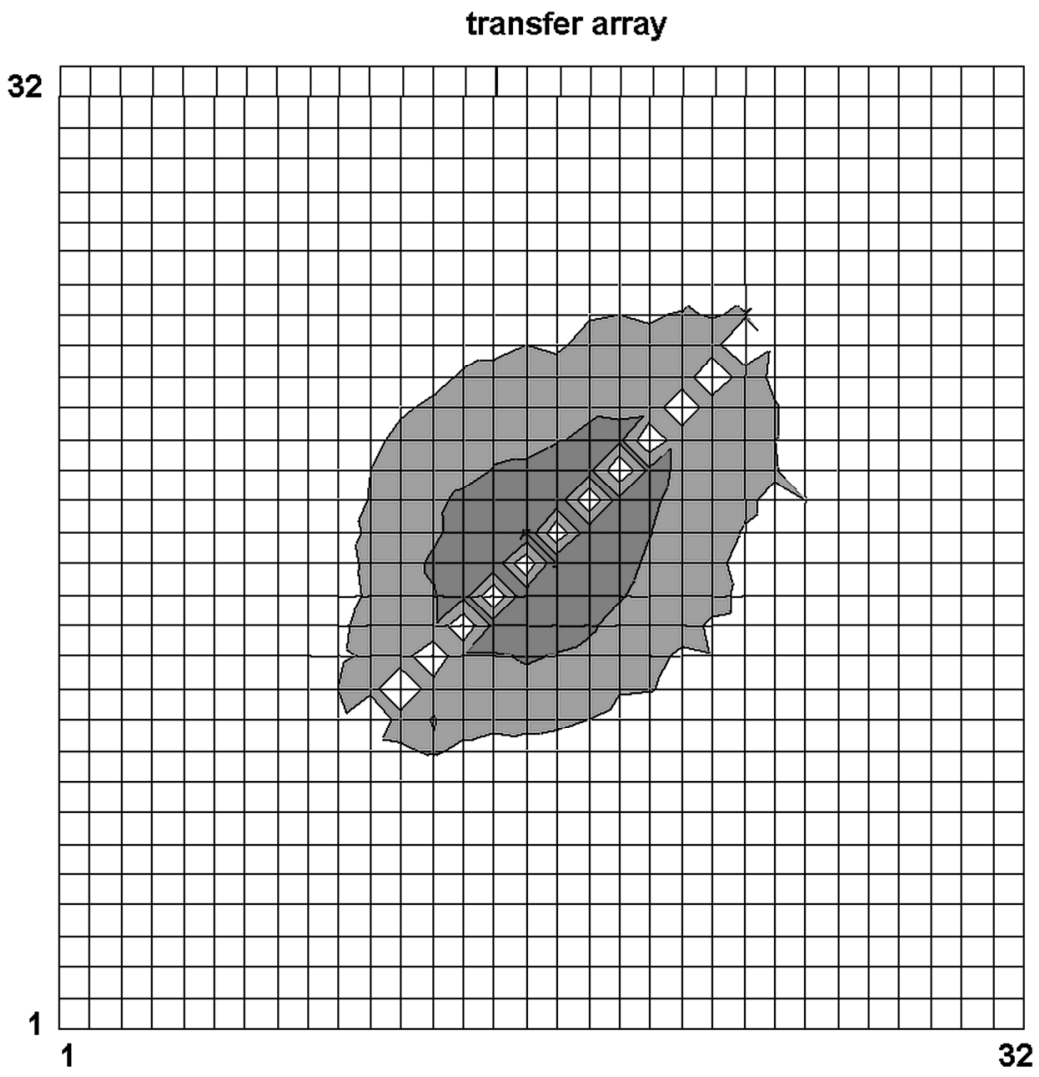

$$
\begin{aligned}
& \square 10^{3}-10^{4} \\
& \square 10^{2}-10^{3} \\
& \square 10^{1}-10^{2} \\
& \square 10^{0}-10^{1}
\end{aligned}
$$

Fig. 29. Transfer Array

Quasi rainflow counting method

32

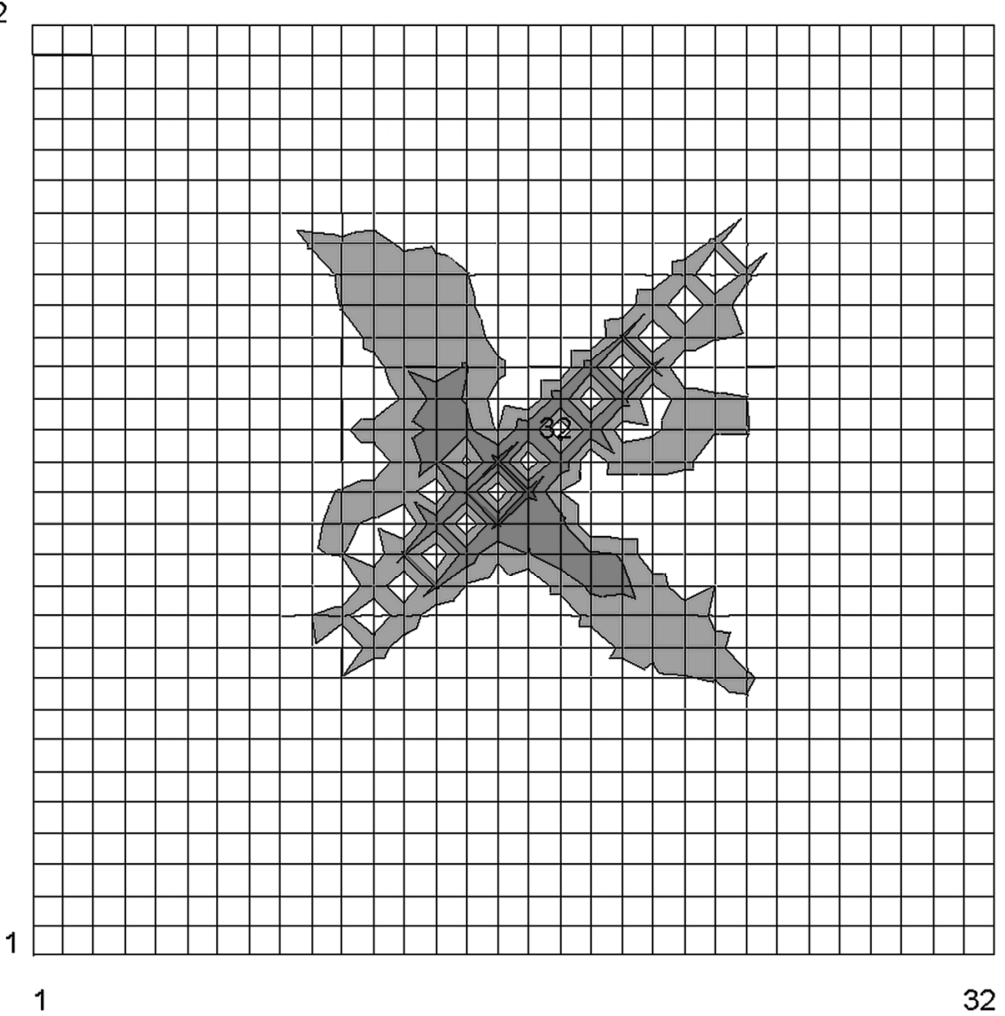

$10^{3}-10^{4}$

ㅁ $10^{2}-10^{3}$

ㄷ $10^{1}-10^{2}$

$\square \quad 10^{0}-10^{1}$

Fig. 30. Quasi rainflow counting method 
Rainflow counting method

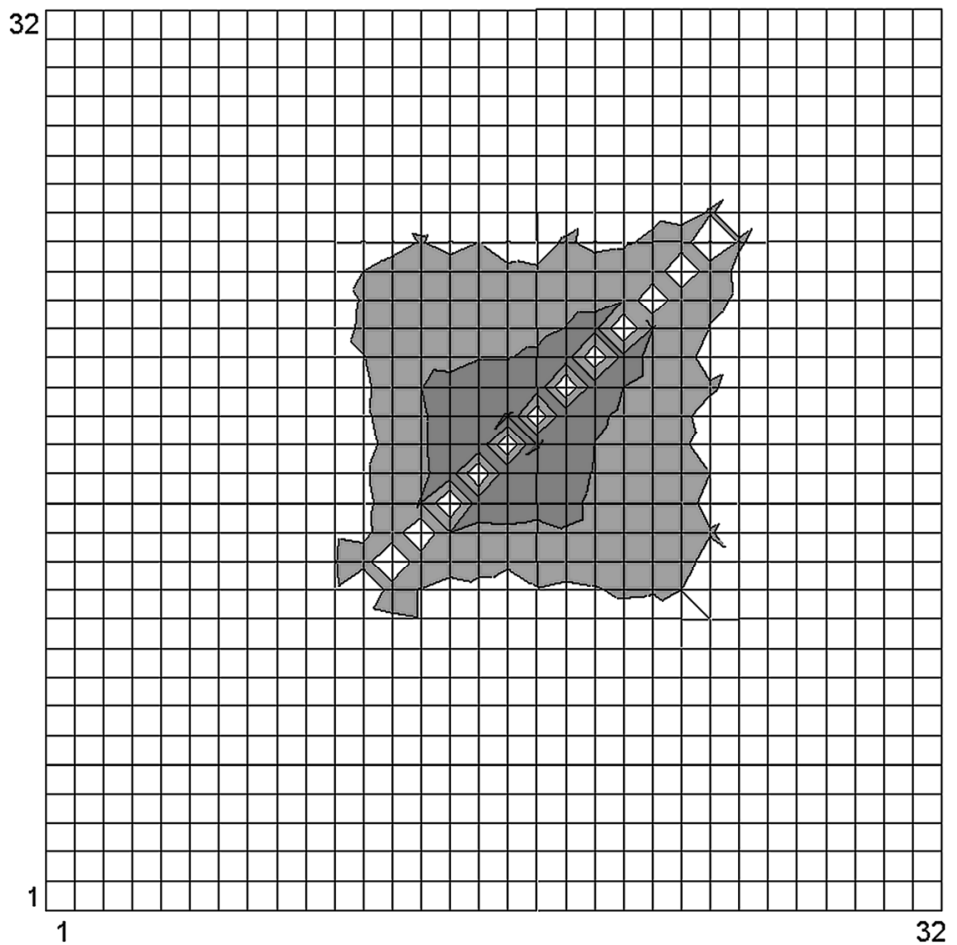

\begin{tabular}{|l|}
$\square 10^{3}-10^{4}$ \\
$\square 10^{2}-10^{3}$ \\
$\square 10^{3}-10^{2}$ \\
$\square 10^{4}-10^{3}$
\end{tabular}

Fig. 31. Rainflow counting method

Full cycles method

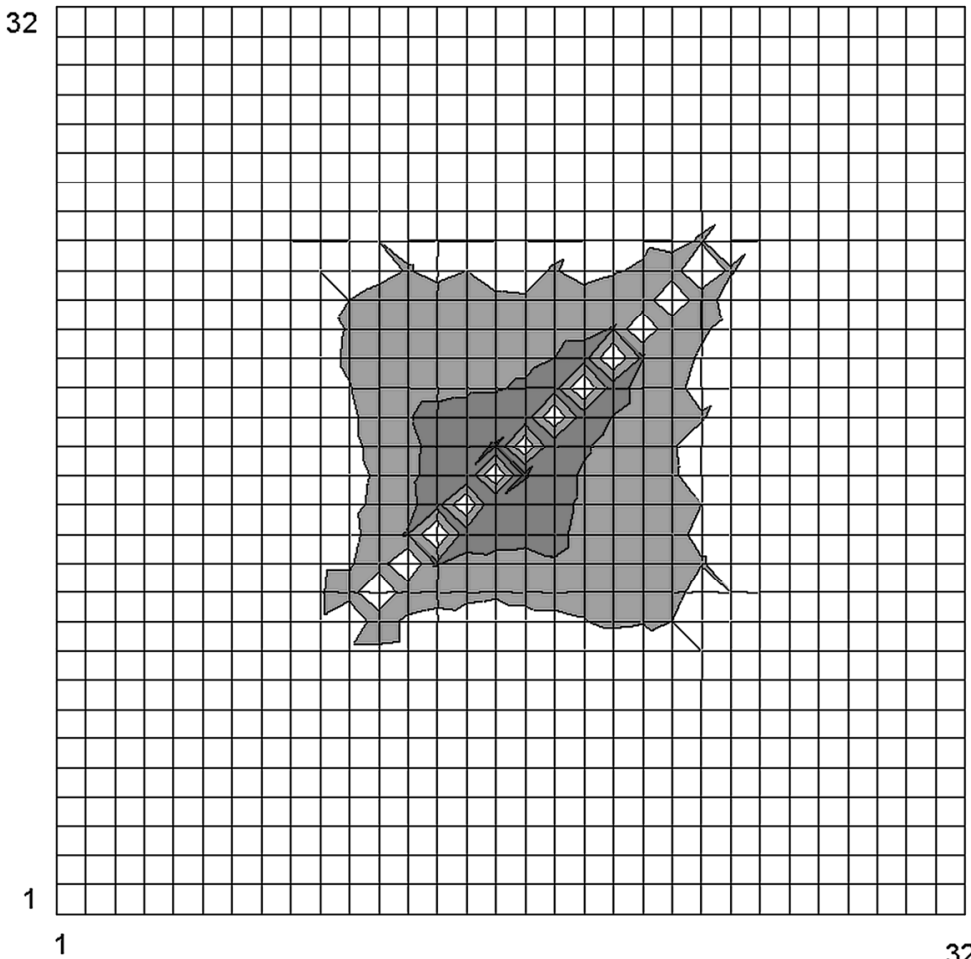

\begin{tabular}{|l}
$\square 10^{3}-10^{4}$ \\
$10^{2}-10^{3}$ \\
$10^{1}-10^{2}$ \\
$10^{0}-10^{1}$
\end{tabular}

Fig. 32. Full cycles method 
Level exceeds counting method

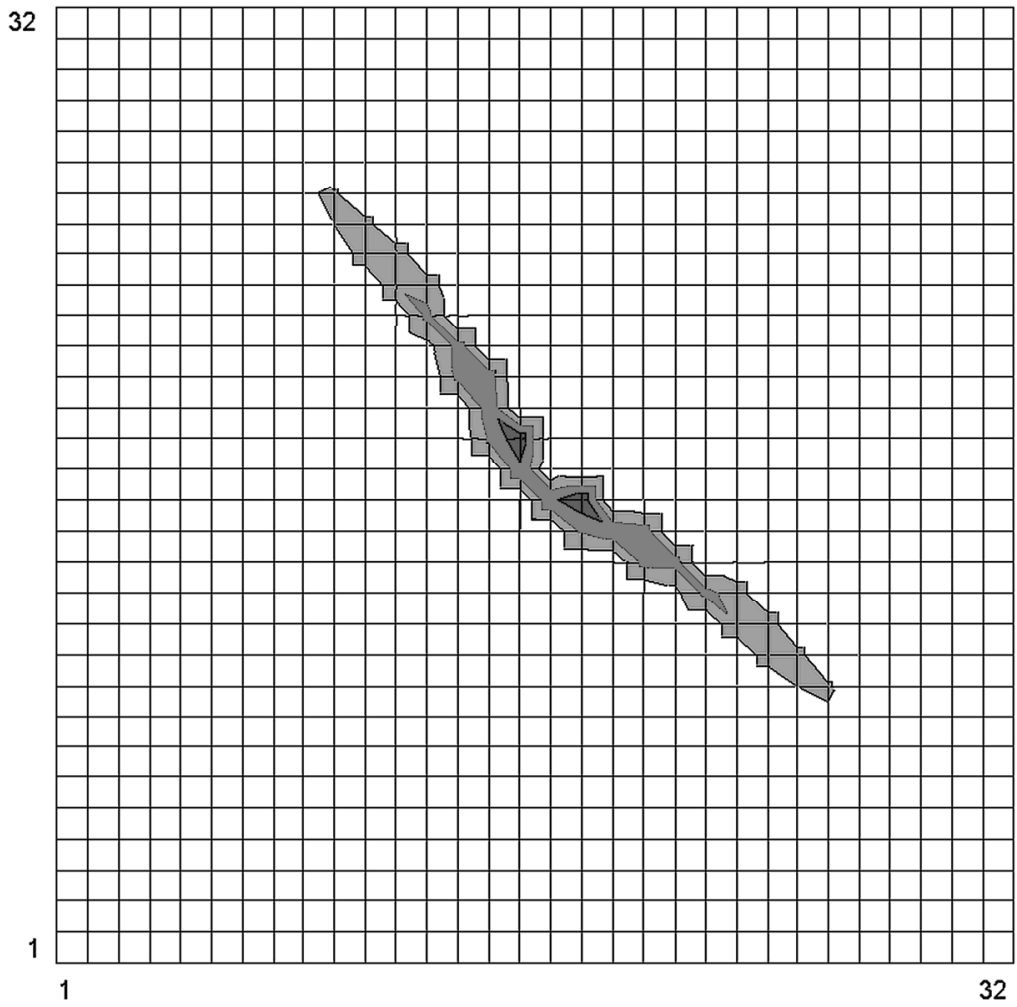

ㅁ $10^{3}-10^{4}$

$\square 10^{2}-10^{5}$

$10^{1}-10^{2}$

ㅁ $10^{\mathrm{U}}-10^{1}$

Fig. 33. Level exceeds counting method

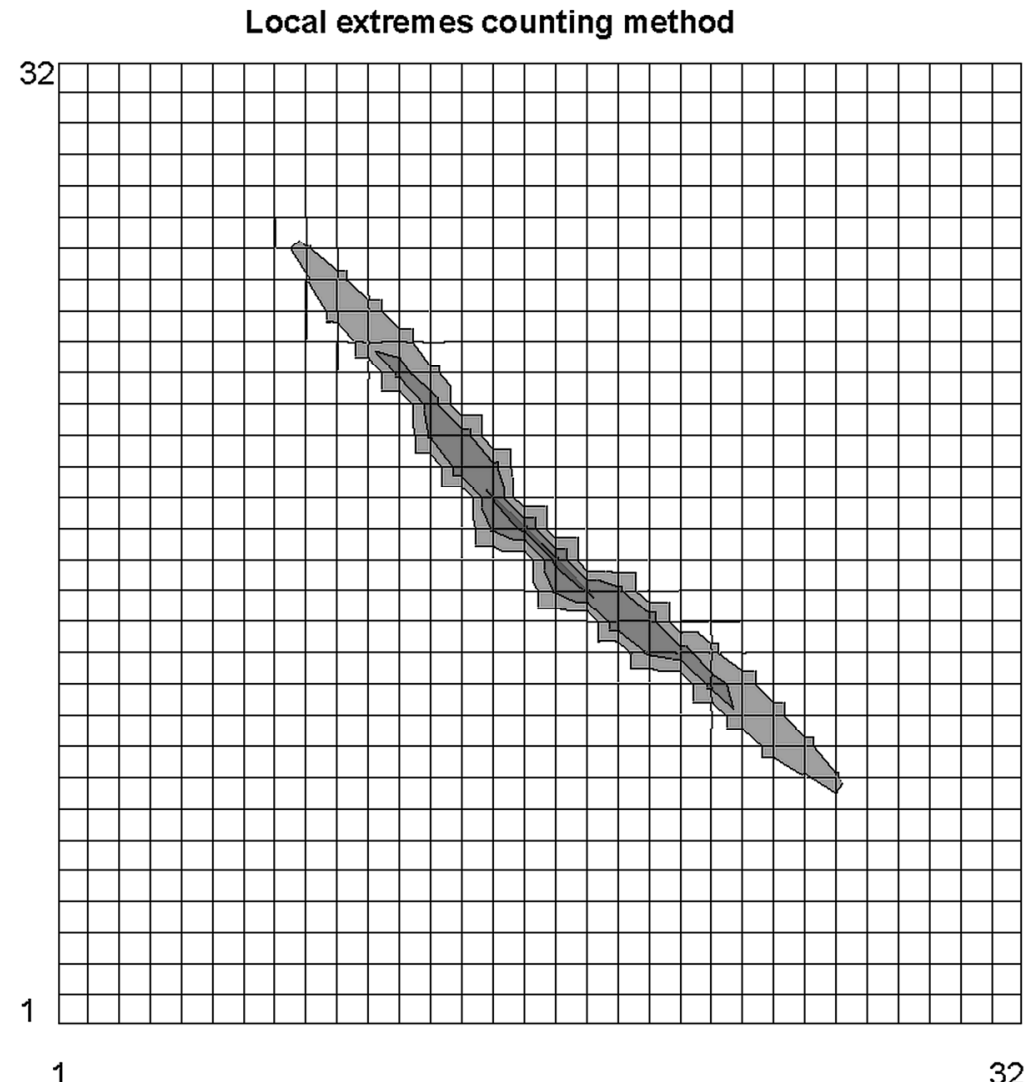

$\square 10^{3}-10^{4}$

$\square 10^{2}-10^{3}$

$\square 10^{1}-10^{2}$

$\square 10^{0}-10^{1}$

Fig. 34. Local extremes counting method 


\section{CONCLUSIONS}

\section{Load spectrum}

The goal of the research was to investigate the load spectrum of a glider landing gear. On the basis of local extremes count method (it gives the biggest values of D coefficient - so it's the most preservative) a block-spectrum of loads was generated (rys. 3.5.1, 3.5.2), which is the answer for the stated problem. The graphs show the mean value of cycles from all the flight experiments. On the horizontal axis: number of cycles, on vertical axis: relative load F/Q where: F- current load exerted on the gear, Q - load exerted on the glider gear when the glider is standing on the airfield, ready to fly.

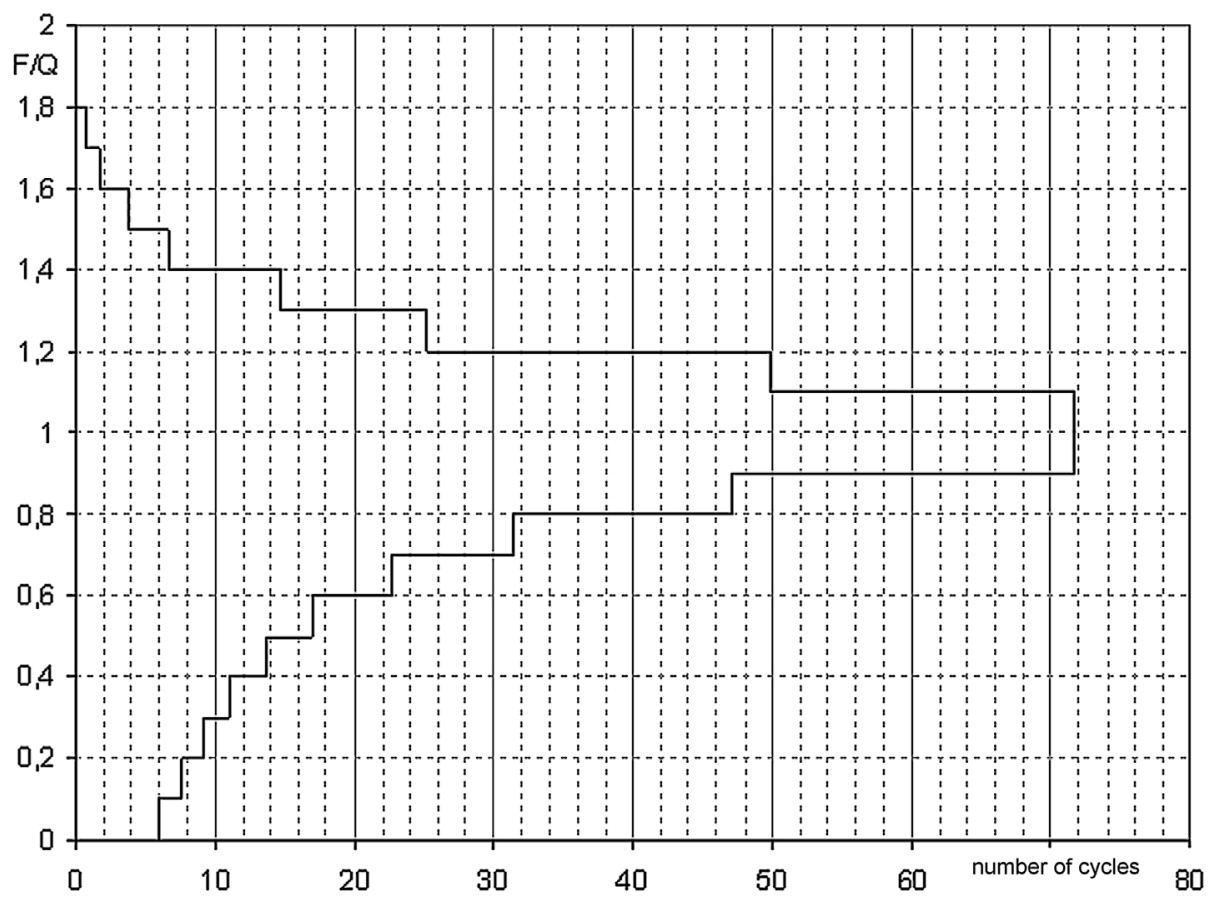

Fig. 35. Load spectrum of the main gear during a single takeoff with a winch.

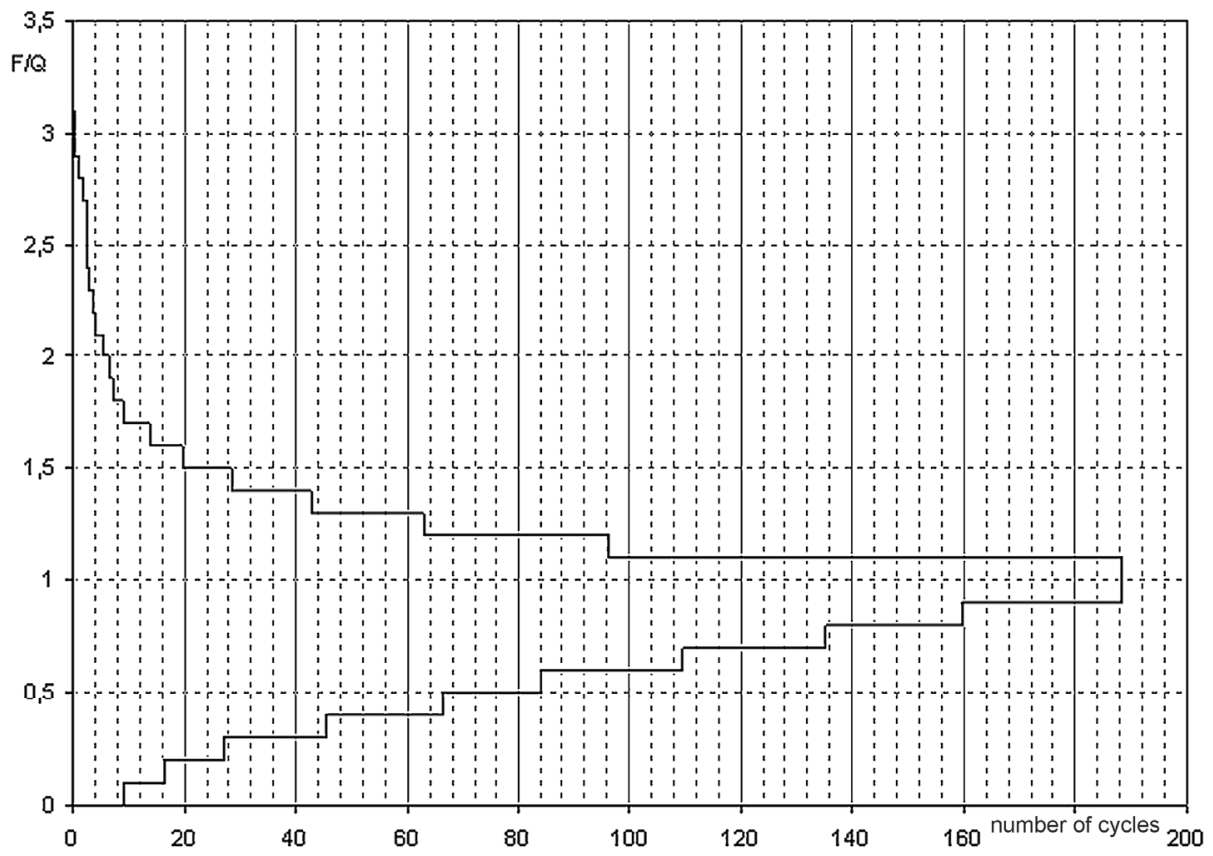

Fig. 36. Load spectrum of the main gear during a single landing on a grassy airfield. 


\section{Comparison of methods processing random series of load spectrums}

For each method an increase of coefficient D was observed in comparison to the transfer matrix. The differences reach a few orders of magnitude and are the biggest for irregular cycles with small values of I coefficient. As written in [3], coefficient $I$ is in the range of 0,5-0,9 for the cycles observed in the nature. For those values of I the difference between the methods investigated decrease but the estimated fatigue strength is still different by several times.

Local extremes count method - gives the highest value of $\mathrm{D}$ coefficient, but because it ignores the sequence of loads it might be expected to be less precise than i.e. rainflow counting method. Besides it requires the mean value of loads.

Level exceeds count method - in two cases the value of D was even smaller than the one in transfer matrix.

Rainflow counting method - is considered as the best one to process the load levels. As the only one includes the cycles sequences, which makes it the most complicated one. Additionally it requires the whole cycle to be kept in the memory while processing.

Full cycles method - gives the results comparable to rainflow counting method and shares it's basic disadvantages - complicated computing, possible only when based on a load level series. Resulting matrix is diagonally symmetrical, which is useful while organizing fatigue tests.

Quasi rainflow counting method - in comparison to other methods, it lowers the results for small values of I coefficient. To generate the matrix a sequence of loads is not necessary only the transfer matrix.

\section{REFERENCES}

[1] Skarbiński A. \& Staniej W. (1965). Projektowane i Konstrukcja Szybowców. Wydawnictwa Komunikacji i Łączności.

[2] Topoliński T. Zmęczenie tworzyw polimerowych. Mechanizmy niszczenia, fenomenologiczne hipotezy procesu zmęczeniowego niszczenia.

[3] Kocańda S. \& Szala J. (1985). Podstawy obliczeń zmęczeniowych. Warsaw: PWN.

[4] Owczarek, W. Spektrum obciqżeń szybowca, praca przejściowa. 